\title{
过渡金属催化的有机嗍试剂对醛酮的不对称加成研究进展
}

\author{
祝东星 ${ }^{a}$ 徐明华 $*, a, b$ \\ ( ${ }^{a}$ 中国科学院上海药物研究所 新药研究国家重点实验室 上海 201203) \\ ( ${ }^{b}$ 南方科技大学化学系 深圳格拉布斯研究院 广东深圳 518055)
}

\begin{abstract}
摘要 手性芳基醇是一类重要的合成砌块, 广泛存在于许多生物活性分子以及天然产物中, 因此, 高效高选择性地构 建该类化合物是有机化学家们一直关注的研究热点. 金属试剂对羰基化合物的不对称加成是构建手性芳基醇的一个简 单高效的方法，其中，有机硼试剂由于其方便易得、稳定、低毒、官能团耐受性好等优点而被广泛用于醄、酮的不对 称加成反应中. 本文综述了过去二十年来过渡金属催化的有机硼试剂对醛、酮的不对称加成反应研究进展, 并介绍了 一些方法在生物活性手性分子合成中的应用.
\end{abstract}

关键词＼cjkstart不对称合成; 手性醇; 有机硼试剂; 过渡金属催化; 不对称加成

\section{Transition Metal-Catalyzed Asymmetric Addition of Organoboron Reagents to Aldehydes and Ketones}

\author{
Zhu, Dong-Xing ${ }^{a} \quad$ Xu, Ming-Hua ${ }^{*, a, b}$ \\ ( ${ }^{a}$ State Key Laboratory of Drug Research, Shanghai Institute of Materia Medica, Chinese Academy of Sciences, \\ Shanghai 201203) \\ $\left({ }^{b}\right.$ Shenzhen Grubbs Institute and Department of Chemistry, Southern University of \\ Science and Technology, Shenzhen, Guangdong 518055)
}

\begin{abstract}
Chiral aryl alcohols are prevalent in a broad range of biologically active compounds, pharmaceutical agents and natural products. They also constitute a broad class of optically active building blocks for the synthesis of important chiral compounds. In recent years, organoboron reagents are widely used in organic synthesis as they possess advantages of ready availability, low toxicity, good air and moisture stability as well as high functional group compatibility. Since the first report of rhodium-catalyzed asymmetric addition of aryl boronic acids to aryl aldehydes in 1998 by Miyaura, the use of organoboron reagents in asymmetric addition to various carbonyl compounds under various transition-metal catalyses has been intensively investigated. Over the past two decades, transition metal-catalyzed asymmetric addition of organoboron reagents to aldehydes and ketones has proved as one of the most direct and powerful methods for accessing versatile optically active alcohols. The development and progress of a wide range of chiral ligands for $\mathrm{Rh}, \mathrm{Ru}, \mathrm{Pd}, \mathrm{Ir}, \mathrm{Cu}, \mathrm{Ni}$ and Co catalysis for asymmetric addition of organoboron reagents to aldehydes and ketones are summarized, and the achievements in enantioselective synthesis of chiral aryl alcohols and their applications in the synthesis of related biocative products are described. Among them, rhodium and ruthenium-catalyzed enantioselective additions have received considerable attention. In the cases of activated carbonyl compounds such as $\alpha$-aryl ketoesters and $\alpha$-diaryl diketones, excellent results can be attained in terms of both yield and enantioselectivity. However, it remains a daunting challenge for highly enantioselective addition to simple unactivated aldehydes and ketones owing to the difficulty in overcoming stereo differentiation. Future efforts in the community would focus on developing new effective transition-metal catalysts in addressing these issues by promoting efficient transformation and controlling excellent enantioselectivity.
\end{abstract}

Keywords asymmetric synthesis; chiral alcohols; organoboron reagents; transition-metal catalysis; asymmetric addition

手性芳基醇结构广泛存在于许多生物活性分子及 天然产物中, 如抗抑郁药物西酞普兰 $(\mathbf{4})^{[1 \mathrm{a}]}$ 、抗组胺药氯
马斯汀 $(5)^{[1 b]}$ 、止咳药氯苯达诺 $(6)^{[1 c]}$ 等都含有手性芳基 醇骨架. 此外，对手性醇类化合物进行简单的衍生化还

\footnotetext{
* Corresponding author. E-mail: xumh@sustech.edu.cn

Received October 10, 2019; revised October 27, 2019; published online November 7, 2019.

Project supported by the National Natural Science Foundation of China (Nos. 21672229, 81521005, 21971103) and the National Science \& Technology Major Project of China (No. 2018ZX09711002-006).

国家自然科学基金(Nos. 21672229, 81521005, 21971103)、国家科技重大专项(No. 2018ZX09711002-006)资助项目.
} 
可以得到其他类型的药物分子如抗过敏药西替利嗪等 (图 1). “沙利度胺” 事件之后, 单一对映体的手性药物 研究受到学术界和工业界的重视 ${ }^{[2]}$. 鉴于手性芳基醇类 化合物及其衍生物展现出的广泛的生物活性, 以及它们 作为重要手性合成砌块在不对称合成中的应用, 发展高 效构建手性芳基醇骨架的方法对手性药物合成以及新 药创制都具有十分重要的意义.

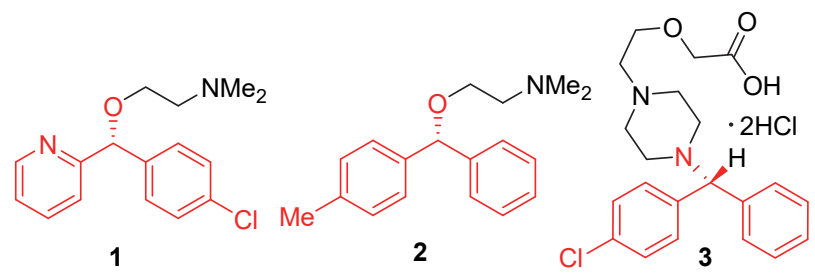

$(R)$-carbinoxamine

(R)-neobenodine

$(R)$-cetirizine
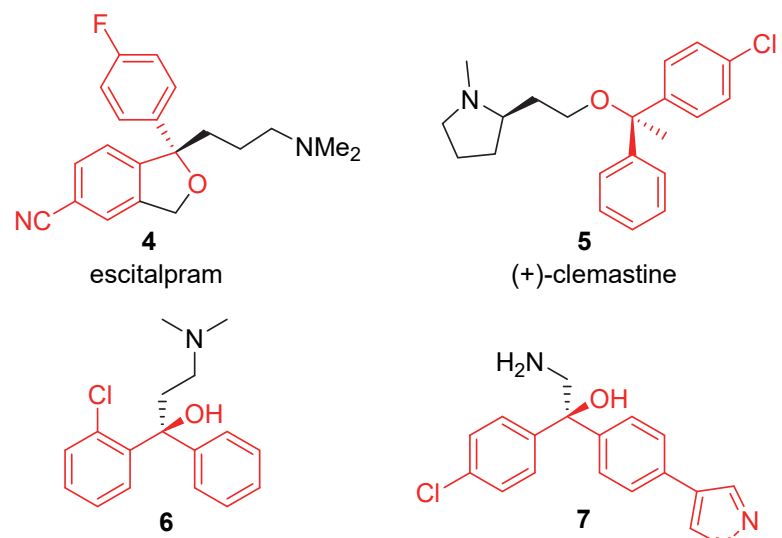

(S)-chlophedianol

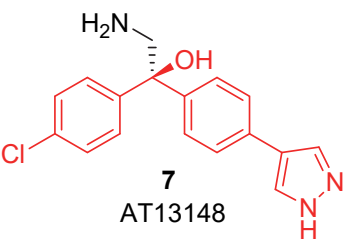

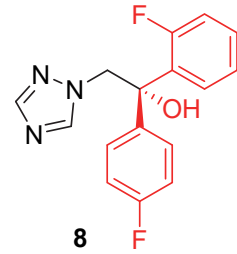

(+)-flutriafol

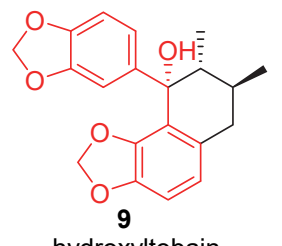

hydroxyltobain
图 1 含手性芳基醇骨架的生物活性分子

Figure 1 Bioactive compounds containing chiral aryl alcohol

与烯烃的不对称双羟化 ${ }^{[3 a, 3 b]}$ 、手性喼酸酯的氧 化 ${ }^{[3 \mathrm{c}]}$ 、环氧化合物的开环 ${ }^{[3 \mathrm{~d}, 3 \mathrm{e}]}$ 以及醇的去对称化 ${ }^{[3 \mathrm{f}]}$ 等构 建手性醇的方法相比, 有机金属试剂如格氏试剂、锂试 剂、有机锌试剂及有机锡试剂等对羰基化合物的不对称 加成，是构建手性醇类特别是手性叔醇类化合物最简单 直接的方法 ${ }^{[4]}$. 然而这些有机金属试剂存在着制备较为 繁琐, 对水和空气敏感, 反应需要在较低的温度下进行, 官能团耐受性差, 以及底物适应性差等特点, 很大程度 上限制了该类方法的应用.

1998 年 Miyaura 小组 ${ }^{[5]}$ 首次报道了铑催化的芳基硼 酸对醛的不对称 1,2-加成, 尽管反应的对映选择性并不 理想 $(41 \% e e)$, 但芳基硼酸方便易得、低毒、对水和空 气稳定、官能团耐受性好等优点引起化学家们的极大关
注和兴趣 ${ }^{[6]}$. 发展高效的催化体系, 解决反应的立体选 择性控制困难的问题成为该领域研究的焦点. 在过去的 二十年里, 化学家们发展了各种不同类型的催化体系来 实现该类反应的立体选择性控制, 本文详细归纳了这一 领域的研究进展和取得的结果.

\section{1 醛的不对称芳基化}

\section{1 铑催化的醛的不对称芳基化}

1998 年 Miyaura 小组 ${ }^{[5]}$ 报道了 Rh(I)催化的芳基硼 酸对醛的加成, 使用膦配体反应可以取得非常好的收 率, 之后他们利用 $(S)-\mathrm{MeO}-\mathrm{MOP}(\mathrm{L1})$ 作为配体进行了 不对称加成的尝试, 得到 $41 \% e e$ 值的产物 12 , 首次实 现了铑催化的芳基嗍酸对醛的不对称加成，开启了过渡 金属催化的有机嗍试剂对羰基化合物的不对称加成研 究的先河, 他们认为在这个反应中水作为质子源可以促 进反应的进行(Eq. 1).<smiles>Cc1cccc2ccccc12</smiles>

10<smiles>Oc1ccccc1</smiles>

11

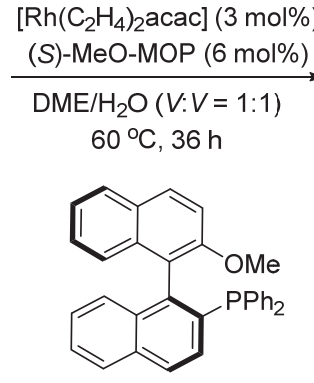

L1

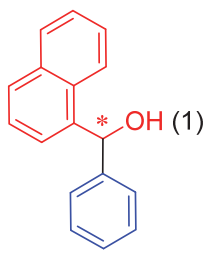

12

$78 \%$ yield $41 \%$ ee
在接下来的几年里，过渡金属催化的芳基硼酸对醛 的不对称加成一直没有报道. 直到 2005 年, Bolm 等 ${ }^{[7]}$ 将平面手性的咪唑鎓盐作为 $\mathrm{N}$ 杂环卡宾( $\mathrm{NHC}$ )的前体用 于 $\mathrm{Rh}(\mathrm{II})$ 催化的芳基硼酸对醛的不对称加成，反应可以 取得最高 38\% ee 值的产物. 研究发现, 配体中的二苯基 氧膦对反应的立体控制很重要，将二苯氧膦换成甲氧基 时反应的立体选择性会出现下降, 在咪唑基团的氮原子 上引入手性基团对部分底物的立体选择性的控制有一 定的帮助(Eq. 2).

2006 年, Aoyama 课题组 ${ }^{[8]}$ 报道了 $\mathrm{Rh}(\mathrm{I}) /(R, R){ }^{i} \mathrm{Pr}-$ Duphos 催化的芳基硼酸对芳基醛的不对称加成，在 $100{ }^{\circ} \mathrm{C}$ 的加热条件下，反应可以以优异的收率得到最高 $66 \% e e$ 值的产物. 同年，该课题组又利用手性双膦配体 $\mathbf{L 5}$ 实现了三价铑催化的芳基嗍酸对芳基醛的不对称加 成, 反应能取得最高 $85 \%$ ee. 有意思的是, ESI-MS 显示 一价铑/膦配体的钠盐可能是其催化的活性形式, 该催 化剂的形成原因可能是膦配体在将三价铑还原成了一 价铑的同时自身被部分氧化成氧膦(Eq. 3). 


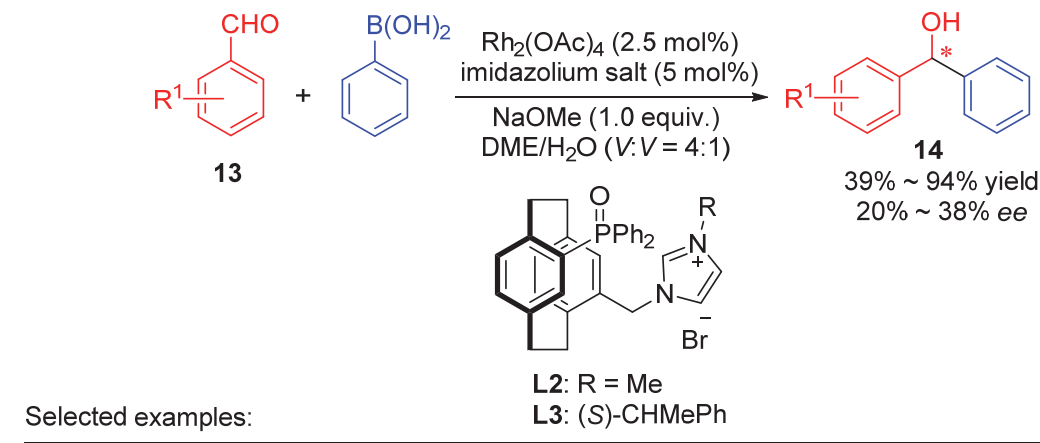

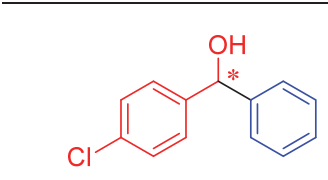

L2: $\quad 72 \%$ yield, $20 \%$ ee L3: $\quad 84 \%$ yield, $29 \%$ ee

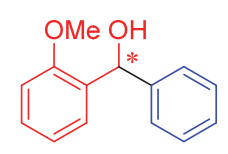

$63 \%$ yield, $23 \%$ ee $68 \%$ yield, $31 \%$ ee<smiles>COc1cccc(C(O)c2ccccc2)c1</smiles>

$51 \%$ yield, $24 \%$ ee $72 \%$ yield, $27 \%$ ee

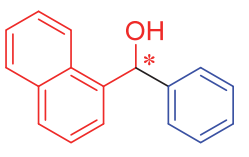

$61 \%$ yield, $29 \%$ ee $85 \%$ yield, $38 \%$ ee

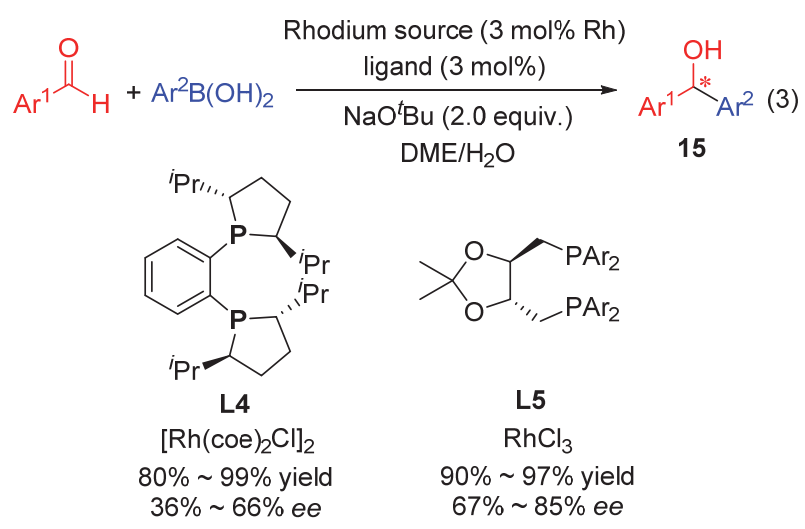

2006 年, 周其林课题组 ${ }^{[9]}$ 将基于手性螺环骨架的单 膦配体 L6 用于一价铑催化的芳基硼酸对醛的不对称加 成反应之中, 取得最高 $87 \% e e$ 值的结果. 该催化体系表 现出较好的底物适应性, 对邻位取代的芳基酫以及芳基 硼酸都可以取得非常优异的收率，而且对于硝基、酯基、 卤素以及杂环都能够耐受. 值得一提的是, 该催化体系 对于兼具 1,2-和 1,4-加成反应位点的肉桂醛也有很好的 化学选择性, 反应可以以 $96 \%$ 收率和 $75 \% e e$ 得到单一 的 1,2-加成产物(Eq. 4).

同年, Minnaard 等 ${ }^{[10]}$ 报道了 $\mathrm{Rh}(\mathrm{I}) /$ 手性双齿亚磷酰 胺 L7 催化的芳基硼酸对酫的不对称加成反应, 可以取 得最高 $75 \% e e$ (Eq. 5). 与单齿亚磷酰胺配体相比, 乙二 胺桥连的双齿亚磷酰胺配体能实现更好地立体选择性 控制; 同时相比其他溶剂, 异丙醇能给出更好的转化率, 这可能与其作为溶剂可以更好地促进中间体硼酸酯 $\mathbf{1 8}$ 转变成产物有关(Scheme 1).

2007 年, Van der Eycken 等 ${ }^{[11 a]}$ 利用 Rh(I)/[2.2.1]庚二 烯骨架的手性双烯配体实现了芳基硼酸对醛的不对称 加成, 他们发现在桥环庚二烯骨架上引入取代基有利于 催化剂反应活性的提高, 而使用醇类溶剂能取得最优的
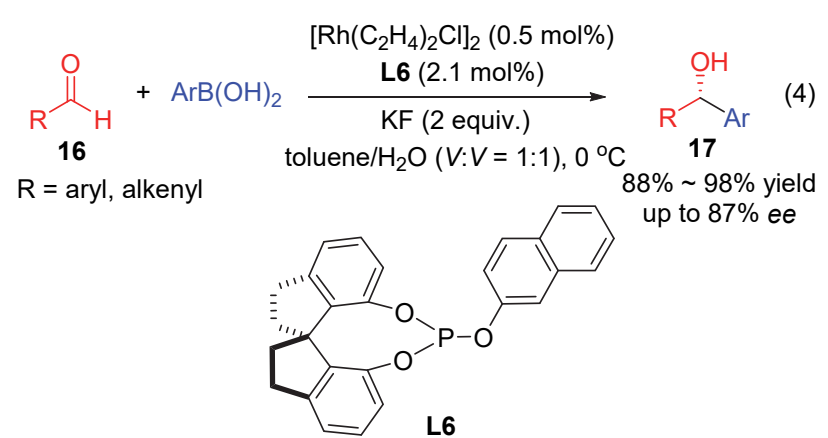
up to $87 \%$ ee

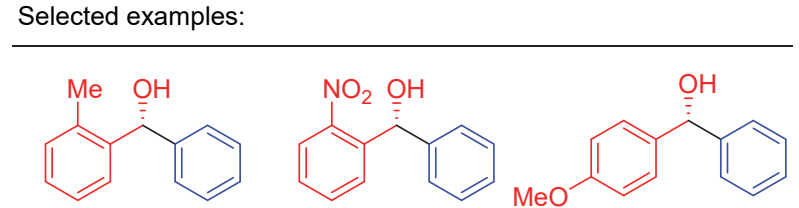

$94 \%$ yield, $80 \%$ ee $\quad 91 \%$ yield, $73 \%$ ee $\quad 90 \%$ yield, $65 \%$ ee<smiles>Oc1ccc(C(O)c2ccccc2Cl)cc1</smiles>

$88 \%$ yield, $85 \%$ ee<smiles>OC(c1cccs1)c1ccccc1Cl</smiles><smiles>Cc1ccccc1C(O)c1ccccc1Cl</smiles>
$98 \%$ yield, $71 \%$ ee $93 \%$ yield, $63 \%$ ee<smiles>OC(c1ccc(-c2ccccc2)cc1)c1ccccc1Br</smiles>
$94 \%$ yield, $87 \%$ ee $96 \%$ yield, $75 \%$ ee

立体选择性(Eq. 6).

2009 年, Hayashi 课题组 ${ }^{[11 b]}$ 将他们发展的[2.2.2]辛 三烯骨架的手性双烯配体 L9 用于醛的不对称芳基化反 应中, 在温和的条件下反应就能顺利进行, 对各种取代 的芳基硼酸以及芳基醛都表现出较好的适应性. 他们认 为桥环上四氟苯基的引入可以减小二面角的大小以及 调整配体的电性，从而可以提高配体与过渡金属配位的 能力. 此外该反应体系在间苯二醛的不对称双芳基化中 也能取得不错的结果(Eq. 7). 

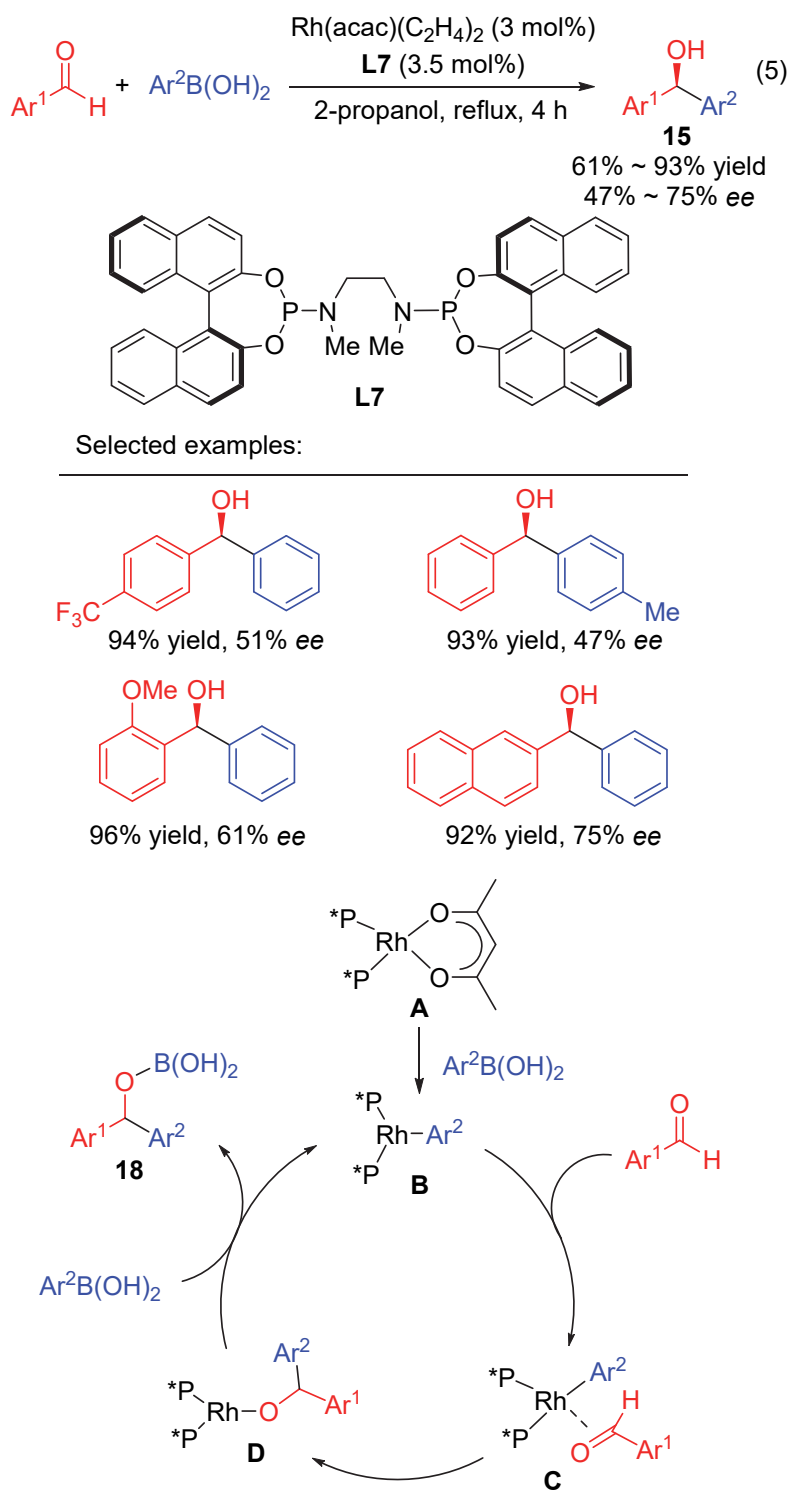

图式 1 推测的反应催化循环

Scheme 1 Proposed catalytic cycle

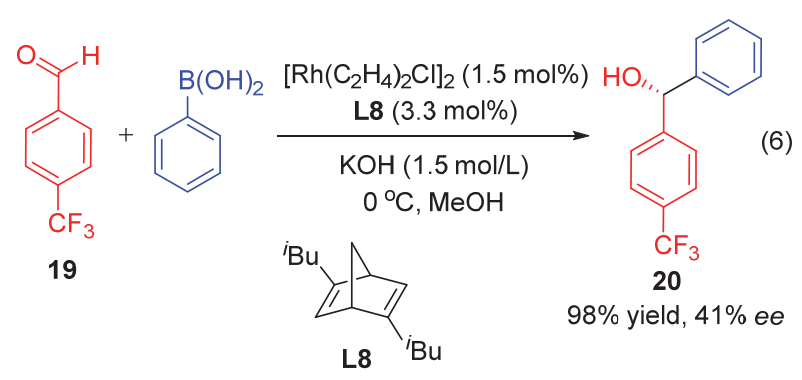

2010 年, Amii 小组 ${ }^{[12]}$ 发展了一类基于手性联二萗 酚(BINOL)骨架的含氟代醇的单膦配体, 该配体在 $\mathrm{Rh}(\mathrm{I})$ 催化的芳基硼酸对醛的不对称加成反应中可以实现中 等到良好的立体选择性控制, 给出最高 $92 \% e e$ 值的结 果. 他们发现配体 L10 中醇羟基以及氟原子的存在对于 催化剂的反应活性和立体选择性的控制都起到十分重
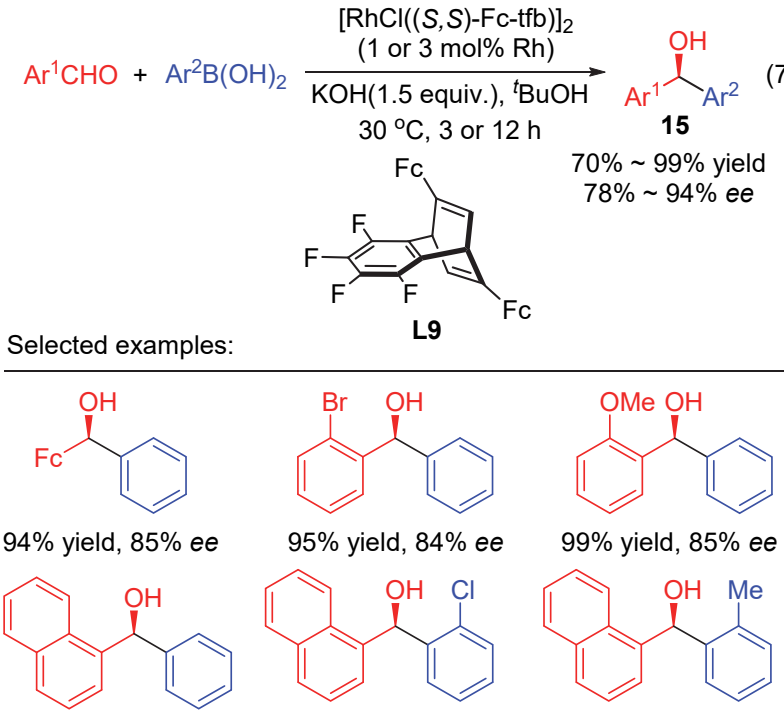

$95 \%$ yield, $84 \%$ ee

$99 \%$ yield, $85 \%$ ee
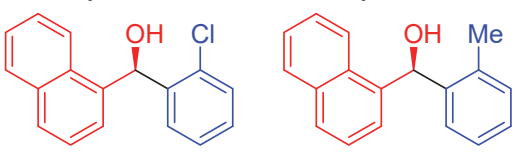

$95 \%$ yield, $86 \%$ ee

$91 \%$ yield, $86 \%$ ee

$87 \%$ yield, $91 \%$ ee

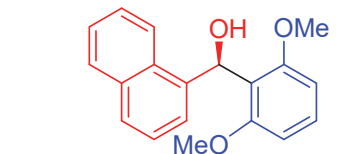

$80 \%$ yield, $84 \%$ ee

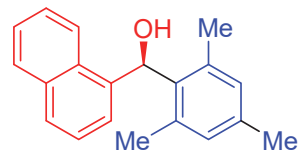

$87 \%$ yield, $94 \%$ ee

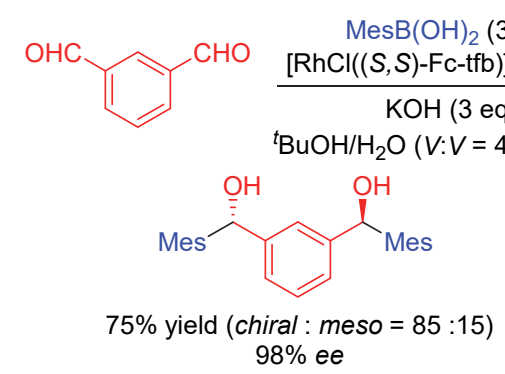

要的作用: 当配体中的醇变成酸时, 催化剂反应活性消 失; 当将与醇连接的三氟甲基变为氢原子或者甲基时， 反应的收率和立体选择性都出现了明显的下降. 而变成 甲基时，反应的立体选择性甚至出现了翻转，一方面可 能是由于三氟甲基的引入使得羟基具有弱酸性，从而增 强了与醛羰基之间的相互作用, 另一方面三氟甲基也参 与了过渡态面选择性的调控(Eq. 8).

马玉道课题组 ${ }^{[13]}$ 利用面手性的 NHC 配体实现了铑 催化的芳基硼酸对醛的不对称加成的立体选择性控制, 该催化体系表现出非常好的反应活性，在 $0.01 \mathrm{~mol} \%$ 催 化剂用量的条件下，反应也能取得 $91 \%$ 的收率，但是立 体选择性并不理想，模板反应最高只能取得 $41 \%$ ee 的 结果. 对配体进行改造, 将苯环上的溴原子换为 $\mathrm{OMe}$ 时，反应的 $e e$ 值可以提高到 $52 \%$, 尝试制备好的 NHC-Rh 配合物作为催化剂, 反应的立体选择性和收率 反而出现明显的下降，通过降低温度超声的方法可以在 一定程度上提高反应的收率和立体选择性. 此外，他们 发现直接使用 $\mathrm{RhCl}_{3}$ 作为催化剂反应可以取得 $58 \%$ 

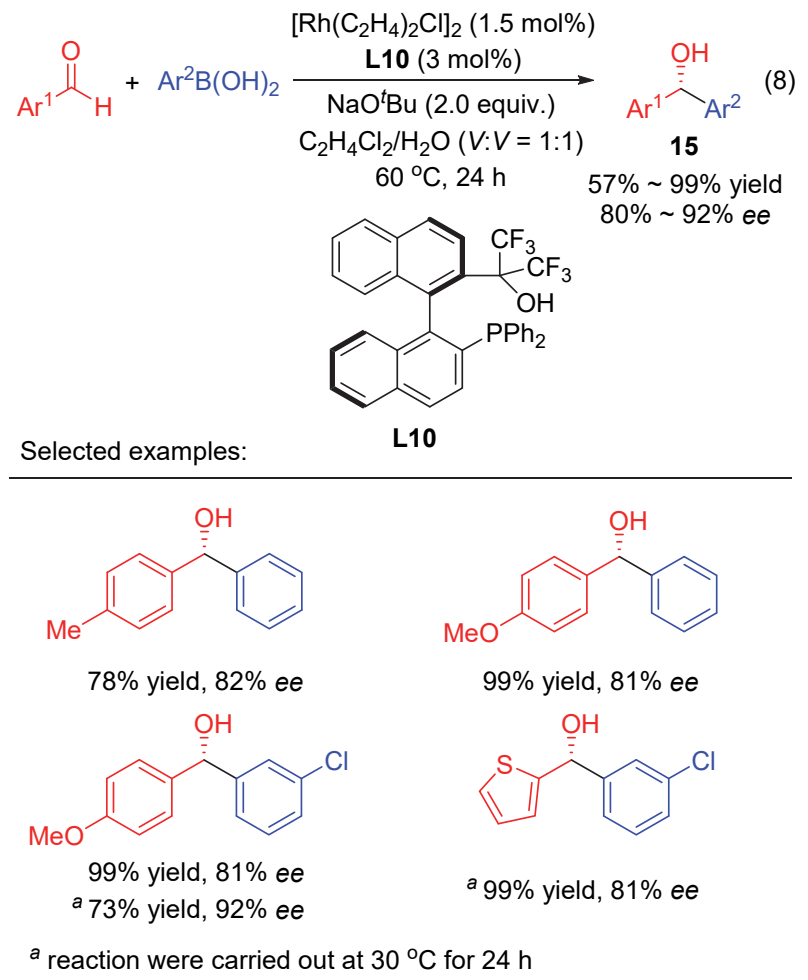

$e e$ 值. 最后他们还对配体分子进行构象限制, 设计了乙 二醇桥连的配体, 收率提高但选择性没有得到改善(Eq. 9).

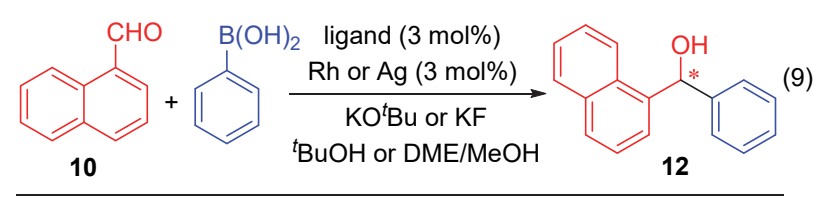

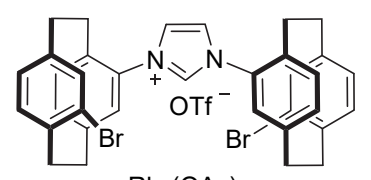

$\mathrm{Rh}_{2}(\mathrm{OAc})_{4}$

$99 \%$ yield, $41 \%$ ee

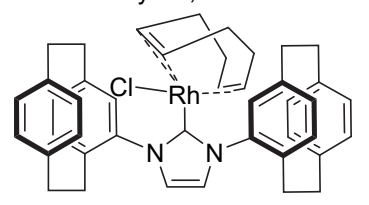

$47 \%$ yield, $36 \%$ ee

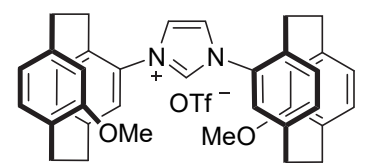

$\mathrm{Rh}_{2}(\mathrm{OAc})_{4}$

$76 \%$ yield, $52 \%$ ee

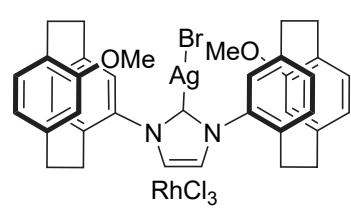

$73 \%$ yield, $58 \%$ ee

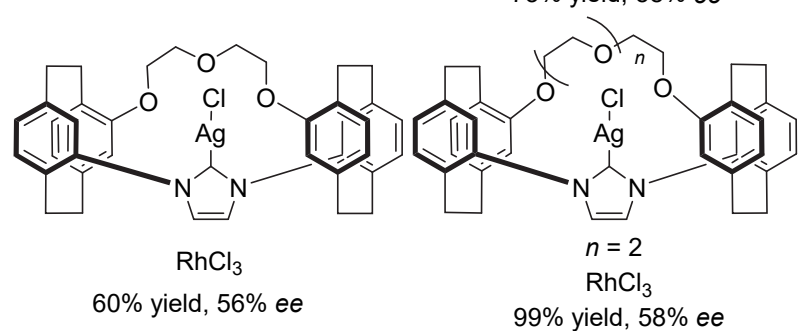

2016 年, $\mathrm{Li}$ 等 ${ }^{[14]}$ 报道了 $\mathrm{Rh}(\mathrm{II})$ / 手性苯并咪唑盐 $\mathbf{L 1 1}$ 催化的醛的不对称加成的例子, 在温和的反应条件下大
部分底物都能给出比较高的收率，但最高也仅能取得 $56 \% e e$ 值. 而当改用醋酸钯作为催化剂时，反应的收率 和立体选择性相比醋酸铑都出现了明显的下降(Eqs. 10, 11).

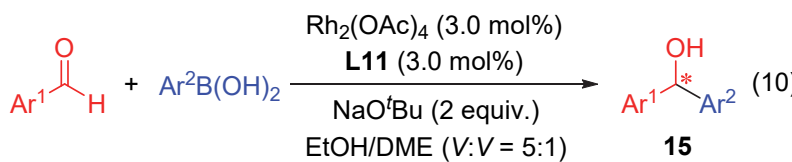

$$
\begin{aligned}
& 50{ }^{\circ} \mathrm{C}, 16 \mathrm{~h} \quad \text { up to } 99 \% \text { yield }
\end{aligned}
$$

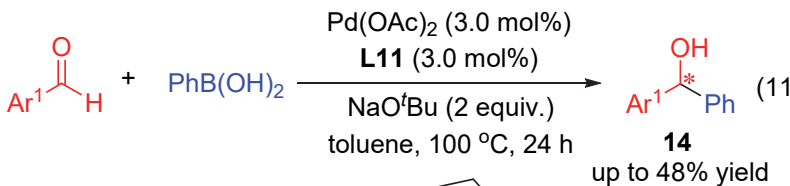

$$
\begin{aligned}
& \begin{array}{r}
\text { up to } 48 \% \text { yield } \\
\text { up to } 7 \% \text { ee }
\end{array}
\end{aligned}
$$

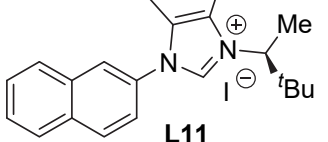

2017 年, 日本的 Kamikawa 和 Ogasawara 课题组 ${ }^{[15]}$ 在他们之前发展的基于面手性 $\pi$-芳烃-铬络合物结构的 膦烯配体的基础上发展了一类在空气中更加稳定的基 于锰的平面手性配体 L12, 该配体除了在铑催化的芳基 嗍酸对烯基酮的不对称 1,4-加成中能取得非常好的收率 和立体选择性外, 在苯硼酸对 1-䒺醛 $\mathbf{1 0}$ 的不对称 1,2加成反应中也能取得很好的结果, 结果表明与环戊二烯 相连的磷上的取代基对反应的收率和立体选择性的控 制起到了十分关键的作用(Eq. 12). 这是目前铑催化的 醛的不对称芳基化取得的最好选择性结果.

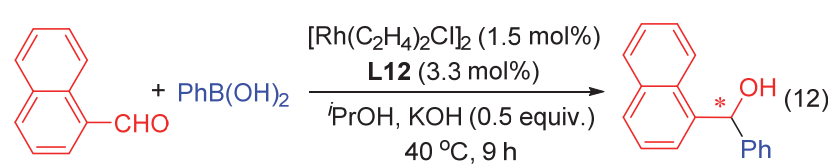

10

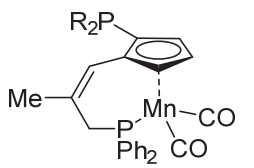

12
L12: $\begin{aligned} \mathrm{R} & =\mathrm{C}_{6} \mathrm{H}_{3}-3,5-\left(\mathrm{CF}_{3}\right)_{2}, 26 \% \text { yield, } 27 \% \text { ee } \\ \mathrm{R} & =\mathrm{C}_{6} \mathrm{H}_{2}-3,5-{ }^{-} \mathrm{Bu}_{2}-4-\mathrm{OMe}, 51 \% \text { yield, } 99 \% \text { ee }\end{aligned}$

\section{2 其他金属催化的醛的不对称芳基化}

在目前已报道的芳基硼酸对醛的不对称加成的工 作中, 铑是最为常见的金属催化剂, 除此之外, 其他地 表含量更为丰富以及更为廉价的金属也被尝试用于醛 的不对称催化加成反应中, 也取得了一些不错的结果.

2009 年, Miyaura 教授课题组 ${ }^{[16 a]}$ 最先报道了钓催化 的芳基碑酸对醛的不对称加成，以 Me-BIPAM (L13)为 配体，反应可以实现很好的立体选择性控制，取得最高 
99\% ee 值. 该反应体系对于杂环芳醛如 2-噻吩甲醛, 2呋喃甲醛甚至是 6-甲氧基-吡啶-3-甲醛都能取得不错的 结果, 这在其他的催化体系中较少见到(Eq. 13). 作者在 文中提到钌与双齿亚磷酰胺的配位模式可能和铑的平 面四边形的配位模式有所区别. 值得一提的是, 该催化 体系同样可以实现烷基醛以及烷基酮酸酯的高效不对 称加成 ${ }^{[16 b, 16 c]}$.

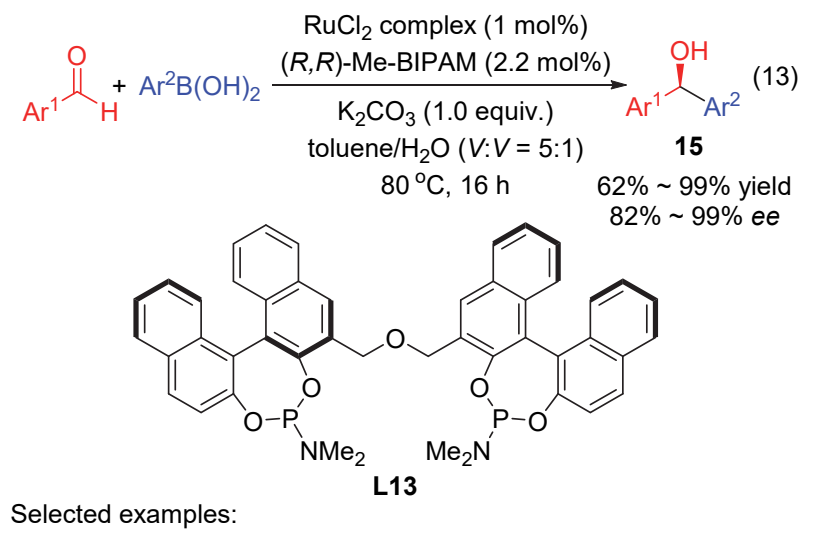

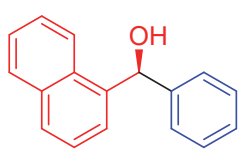

$70 \%$ yield, $98 \%$ ee

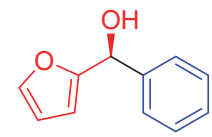

$92 \%$ yield, $82 \%$ ee

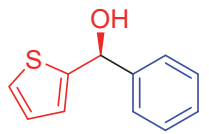<smiles>COc1ccncc1[C@@H](O)c1ccccc1</smiles>

$95 \%$ yield, $96 \%$ ee
$78 \%$ yield, $92 \%$ ee

2016 年, Paquin 小组 ${ }^{[17]}$ 将上述催化体系进一步拓展 到五氟放基取代的芳基醛 21 的不对称加成反应中, 高 效地构建了一系列五氟颈基取代的手性二芳基醇类化 合物 22, 取得最高 $98 \%$ ee 值的结果(Eq. 14).

汤文军课题组 ${ }^{[18]}$ 利用钌/手性单膦配体 $\mathbf{L 1 4}$ 的催化

$$
\begin{aligned}
& {\left[\mathrm{Ru}(p \text {-cymene }) \mathrm{Cl}_{2}\right]_{2}(3.0 \mathrm{~mol} \%)} \\
& \frac{(R, R)-\text { Me-BIPAM }(6.6 \mathrm{~mol} \%)}{\mathrm{K}_{2} \mathrm{CO}_{3} \text {, toluene/ } \mathrm{H}_{2} \mathrm{O}(\mathrm{V}: \mathrm{V}=4: 1)}
\end{aligned}
$$<smiles>CNp1oc2ccc3ccccc3c2c2c(cc(COCc3cc4ccccc4c4c3OP(N(C)C)O4)c3ccc4ccccc4c32)o1</smiles>
L13
22 up to $94 \%$ yield up to $98 \%$ ee
体系也实现了芳基硼酸对醛的不对称加成(Eq. 15). 在 机理探讨过程中, 他们发现产物的 $e e$ 值和配体的 $e e$ 值 呈线性关系，这表明催化剂中钓和单膦配体是 $1: 1$ 配 位的，通过对催化剂活性物种进行单晶培养发现，钓除 了和配体中的磷配位外, 还和其中与氧连接的苯基配位 (Eq. 14). 基于此方法, 他们以醛 $\mathbf{2 3}$ 为底物，实现了选择 性磷酸二酯酶抑制剂 CDP-840 关键中间体的合成 (Scheme 2).

最近，汪君课题组 ${ }^{[19]}$ 通过氧杂苯并降冰片烯的不 对称膦氢化构建了一类含氧桥的手性膦配体，并成功将 其用于钓催化的芳基硼酸对醛的不对称加成反应中，取 得了中等到优秀的收率和对映选择性. 研究发现钓和配 体 L15 的比例很重要, 两者摩尔比为 $1: 1$ 时的结果要 优于 $1: 2$ 的结果, 机理研究表明钉同时与配体中的磷 和桥环上的氧配位(Eq. 16).

2007 年, Aoyama ${ }^{[20 a]}$ 报道了 $\mathrm{Ni}(\operatorname{cod})_{2} /(R, R)$-Et-Duphos (L16)催化的芳基硼䣶对芳基醛的不对称加成的例 子, 在嗍䣶作为嗍源, $\mathrm{NaO}^{t} \mathrm{Bu}$ 作为碱, $100{ }^{\circ} \mathrm{C}$ 条件下, 反应可以以最高 $93 \%$ 的收率以及 $78 \% e e$ 得到手性的二 芳基醇类化合物. 随后，他们用方便易得的芳基氟硼酸 钾代替嗍酐，发现反应在无外加碱的条件下也能顺利进 行, 并能给出最高 $81 \% e e$ 值的结果 ${ }^{[196]}$ (Eq. 17).

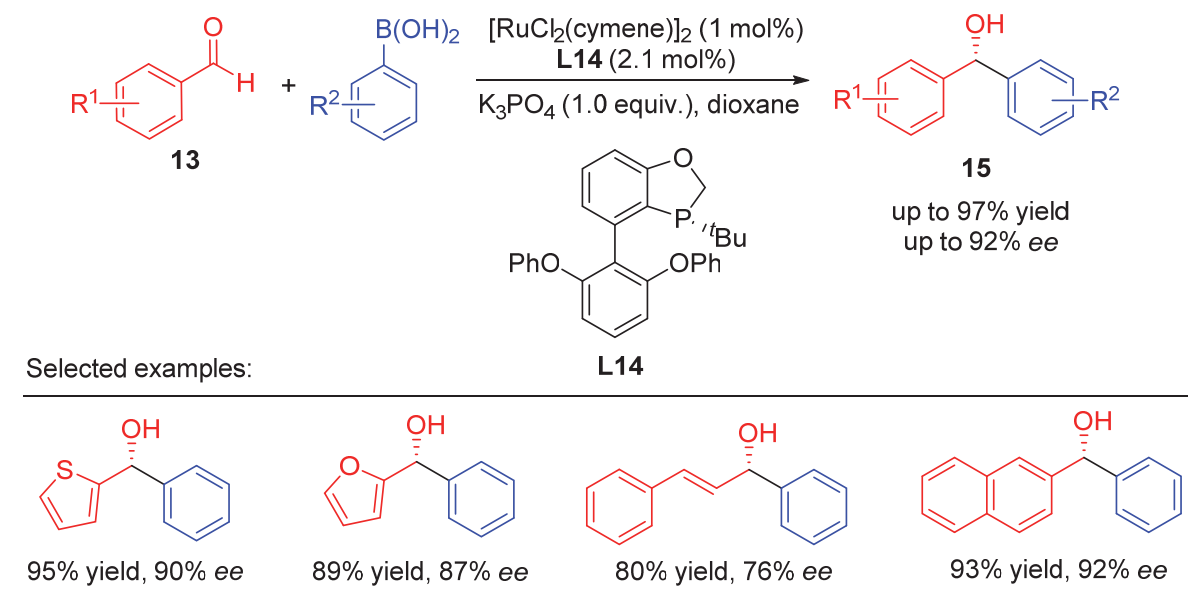


<smiles>COc1ccc(C=O)cc1OC1CCCC1</smiles>

23

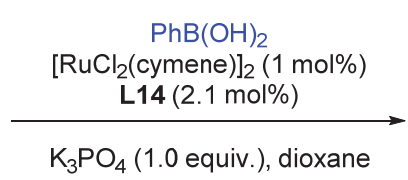

$\mathrm{K}_{3} \mathrm{PO}_{4}$ (1.0 equiv.), dioxane<smiles>COc1ccc([C@@H](O)c2ccccc2)cc1OC1CCCC1</smiles>

$95 \%$ yield, $89 \%$ ee<smiles>COc1ccc(C(Cc2ccncc2)c2ccccc2)cc1OC1CCCC1</smiles>

CDP-840

图式 2 CDP-840 的合成

Scheme 2 Synthesis of CDP-840
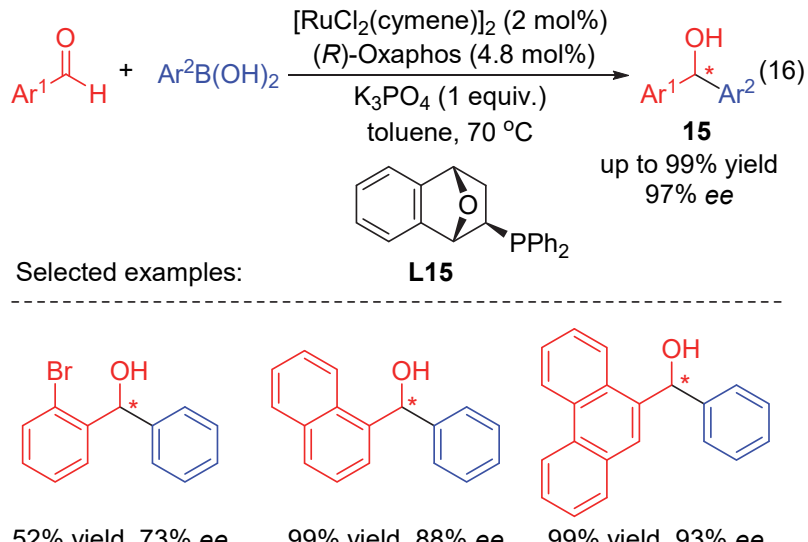

$52 \%$ yield, $73 \%$ ee $\quad 99 \%$ yield, $88 \%$ ee $\quad 99 \%$ yield, $93 \%$ ee

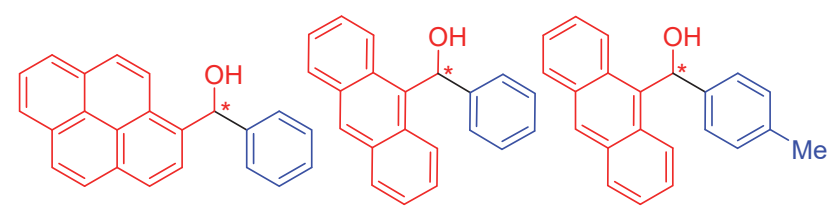

$98 \%$ yield, $90 \%$ ee $\quad 99 \%$ yield, $97 \%$ ee $\quad 94 \%$ yield, $96 \%$ ee

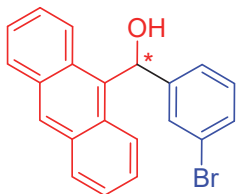

$98 \%$ yield, $97 \%$ ee

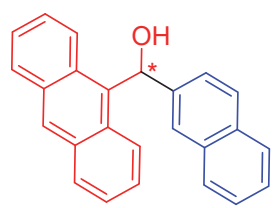

$98 \%$ yield, $96 \%$ ee

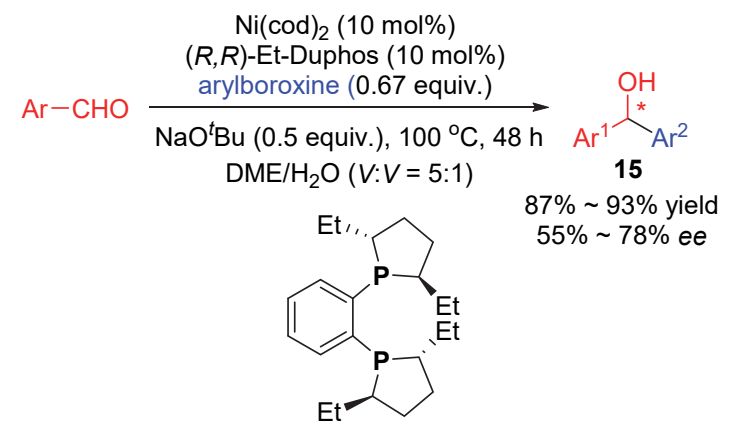

L16

Selected examples:

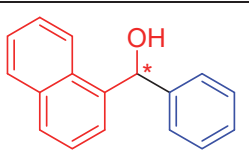

$93 \%$ yield, $68 \%$ ee

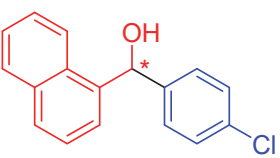

$87 \%$ yield, $66 \%$ ee

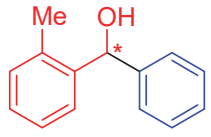

$91 \%$ yield, $78 \%$ ee
2010 年, Cheng 课题组 ${ }^{[21]}$ 利用廉价的钴作为催化剂 实现了芳基嗍酸对醛的加成, 在以 $(R, R)-\mathrm{BDPP}(\mathbf{L 1 7})$ 作
为手性配体的反应条件下,可以取得最高 $99 \% e e$ 的结果, 该催化体系表现出很好的底物适应性，无论是氧基、硝 基取代的醛，还是大位阻的 1-菜醛亦或是脂肪醛都能取 得不错的结果，同时对于大位阻的 2-位取代的芳基硼酸 反应也能取得优异的收率和对映选择性(Eq. 18).
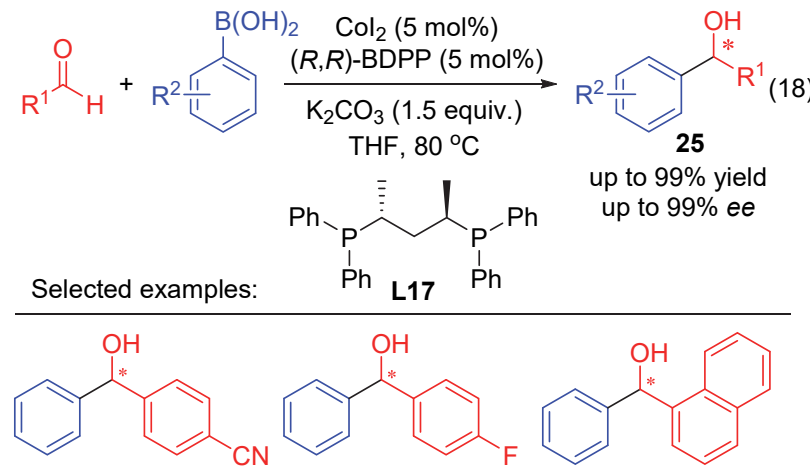

$97 \%$ yield, $92 \%$ ee $\quad 95 \%$ yield, $99 \%$ ee $\quad 77 \%$ yield, $89 \%$ ee

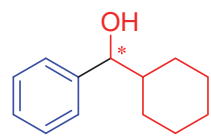

$84 \%$ yield, $97 \%$ ee

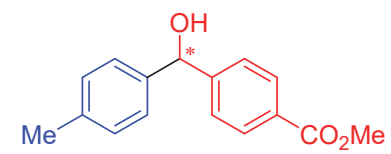

$95 \%$ yield, $91 \%$ ee<smiles>COc1ccccc1C(O)c1ccc(C(C)=O)cc1</smiles>

$92 \%$ yield, $90 \%$ ee

此外钯作为催化剂也被用于芳基硼酸对醛的不对 称加成反应之中 ${ }^{[22]}$, 但结果并不理想, 取得相对较好结 果的是 Shi 课题组 ${ }^{[22 c]}$ 报道的基于联荎二胺(BINAM)骨 架的氮杂卡宾钯络合物催化的例子，反应可以取得最高 $65 \%$ ee 值的结果 (Eq. 19).

\section{2 靛红的不对称芳基化}

手性的 3-羟基吲哚酮是一类非常重要的结构单元, 这类骨架存在于许多具有生物活性的天然产物和药物 分子中如: 化合物 26 是一种非常有效的生长激素促分 泌素 ${ }^{[23]}$, 化合物 27 是一类 Maxi-K 通道激活剂(图 2) ${ }^{[24]}$, 因此，此类手性分子骨架的高效合成一直是一个研究热 点, 受到有机和药物化学家们的广泛关注. 过渡金属催 化的芳基硼酸对靛红的不对称加成是构建此类结构最 

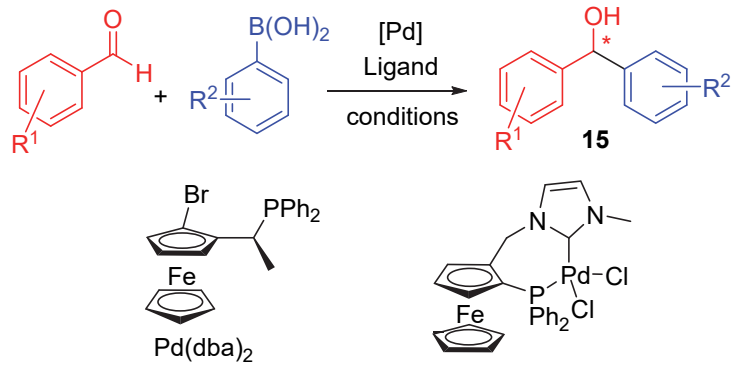

up to $99 \%$ yield, $11 \%$ ee

$69 \%$ yield, $13 \%$ ee

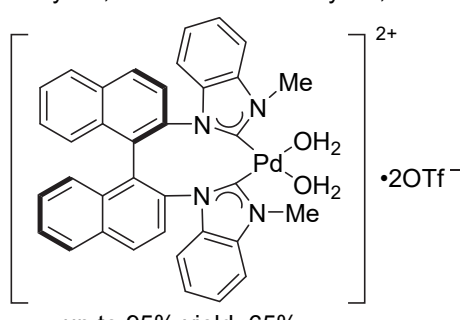

up to $95 \%$ yield, $65 \%$ ee

直接和高效的方法.<smiles></smiles><smiles>O=C1Nc2cc(C(F)(F)F)ccc2[C@]1(O)c1cc(Cl)ccc1O</smiles>

图 2 含 3-羟基吲哚的活性分子

Figure 2 Biologically active molecules containing 3-hydroxy2-oxindoles

\section{1 铑催化的靛红的不对称芳基化}

2006 年 Hayashi 等 ${ }^{[25]}$ 首次报道了 $\mathrm{Rh}(\mathrm{I})$ /单齿膦配体 MeO-MOP (L1)催化的靛红的不对称芳基化的例子, 在 温和的条件下能以中等到优秀的收率和对映选择性得 到一系列光学活性的 3-羟基吲哚酮 29, 对于靛红氮上 没有保护基的底物也能取得 $87 \%$ 的 ee 值. 值的一提的 是, 该反应条件对于靛红的苯乙烯基化也可以取得不错 的结果(Eq. 20).

同年, Feringa 和 Minnaard 等 ${ }^{[26]}$ 利用手性亚磷酰胺 配体也实现了 $\mathrm{Rh}(\mathrm{I})$ 催化的苯硼酸对靛红的不对称芳基 化立体选择性的调控, 反应可以以几乎定量的收率得到 $55 \% e e$ 的产物 31, 31 的 ee 值可通过结晶提高到 $94 \%$ (Eq. 21).

2012 年, 廖建课题组 ${ }^{[27]}$ 利用他们发展的手性磷-亚 砜配体 L19, 同样实现了靛红的不对称芳基化的立体选 择性的控制, 取得最高 $92 \% e e$ 值的结果. 除了邻位取代 的芳基硼酸可以取得较为优异的结果外, 该反应体系对 于氮上没有保护的靛红也可以取得不错的结果, 这为产 物的进一步衍生化提供了便利(Eq. 22).

近年来, 杜海峰课题组 ${ }^{[28 \mathrm{a}]}$ 发展了一系列简单的烯 烃配体, 2014 年, 他们将发展的硫烯配体 L20 用于铑催

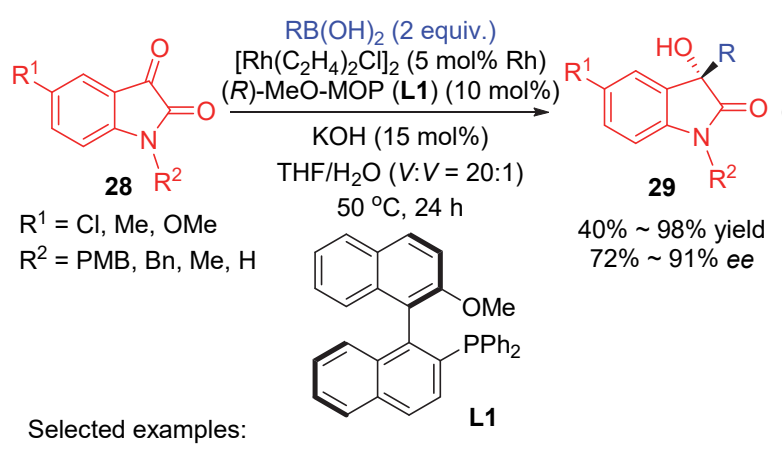

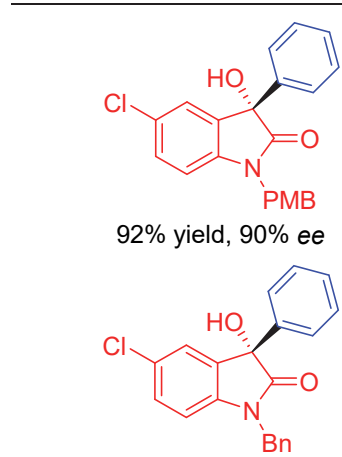

$80 \%$ yield, $89 \%$ ee

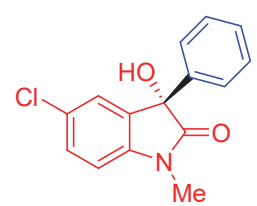

$83 \%$ yield, $88 \%$ ee

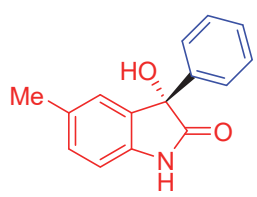

$49 \%$ yield, $87 \%$ ee
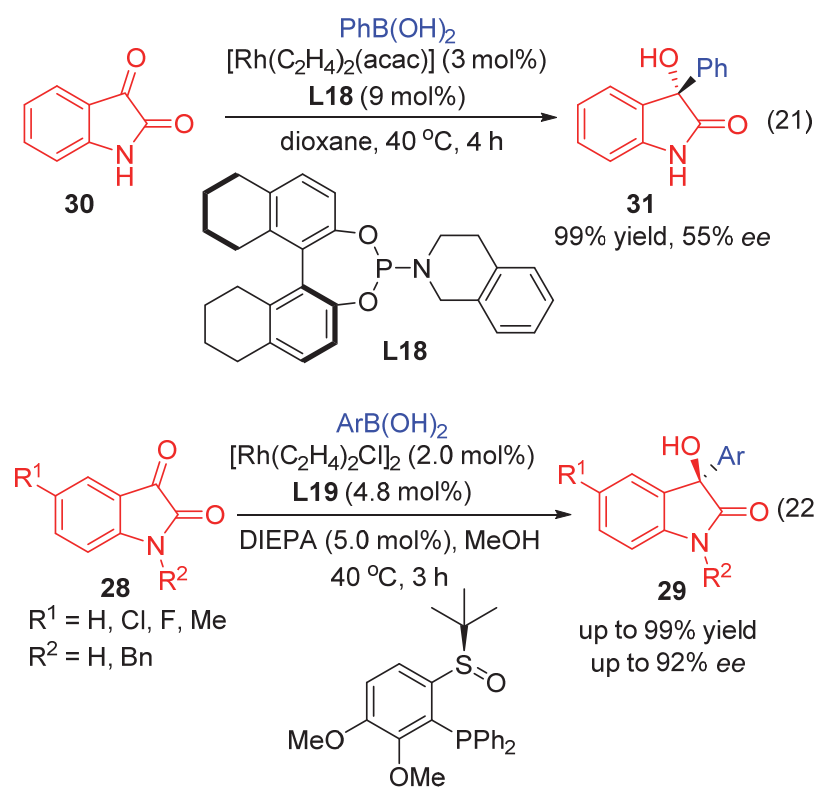

Selected examples:

L19

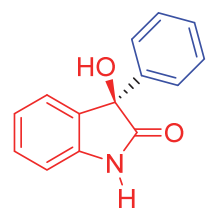

$97 \%$ yield, $85 \%$ ee<smiles>O=C1Nc2ccc(Cl)cc2[C@@]1(O)c1ccc(F)cc1</smiles>

$98 \%$ yield, $87 \%$ ee<smiles>Cc1ccccc1[C@@]1(O)C(=O)Nc2ccc(Cl)cc21</smiles>

$95 \%$ yield, $92 \%$ ee<smiles>Cc1cccc([C@]2(O)C(=O)N(Cc3ccccc3)c3ccc(Cl)cc32)c1</smiles>

$99 \%$ yield, $91 \%$ ee 
化的芳基硼酸对靛红的不对称加成之中, 对于膦配体以 及 $\mathrm{NHC}$ 结果都不理想的大位阻的硼酸, 硫烯配体能取 得中等的选择性 ${ }^{[28 b]}$. 此外, 对于靛红氮上没有保护的 底物, 反应也表现出较好的适应性(Eq. 23). 他们以此反 应为依托, 将相应产物 34 重结晶, 再通过 3 步反应合成 了对加压素或催产素依赖疾病具有预防作用的生物活 性分子 35 (Scheme 3).

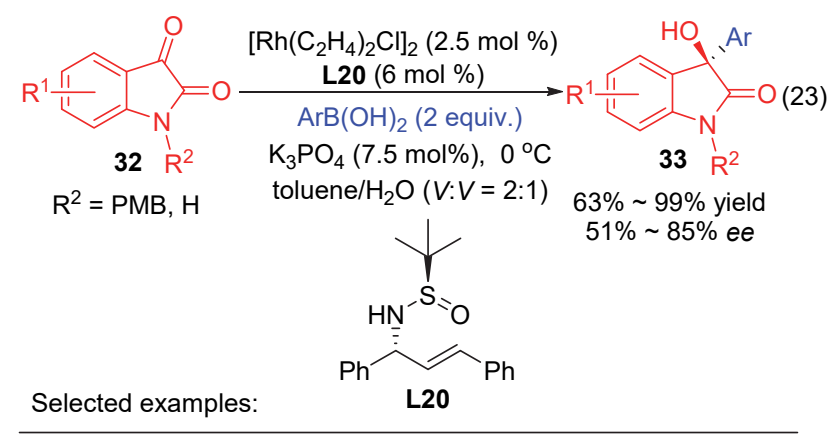

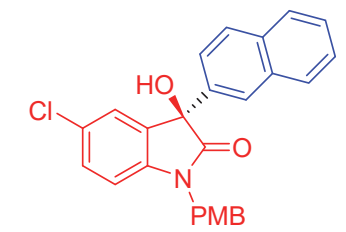

$60 \%$ yield, $60 \%$ ee

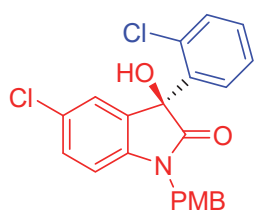

$77 \%$ yield, $79 \%$ ee

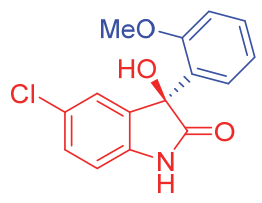

34

$76 \%$ yield, $95 \%$ ee after a recrystallization

(1) 8-quinolinesulfonyl chloride ${ }^{t}$ BuOK, DMF, r.t. $\sim 50^{\circ} \mathrm{C}, 22 \mathrm{~h}$

(2) $\mathrm{ClCO}_{2} \mathrm{Ph}, \mathrm{CH}_{2} \mathrm{Cl}_{2}$, pyridine

(3) 1-(2-pyridyl)piperazine

$37 \%$ yield for three steps<smiles>COc1ccccc1[C@]1(OC(=O)N2CCN(c3ccccn3)CC2)C(=O)N(S(=O)(=O)c2cccc3cccnc23)c2ccc(Cl)cc21</smiles>

图式 3 生物活性分子合成

Scheme 3 Synthesis of biologically active molecule

2016 年, Burke 等 ${ }^{[29]}$ 利用 $(R)$-BINAP 作为配体实现 了 $\mathrm{Rh}(\mathrm{I})$ 催化的芳基硼酸对三氮唑取代靛红底物 36 的不 对称加成, 反应可以取得最高 $95 \% e e$ 值的产物. 由于底 物中的邻二羰基以及三氮唑都有可能干扰铑和配体的
配位，因此在反应之前需要先制备好金属络合物，此外 选择大位阻的有机胺作为碱对反应的收率也有一定的 帮助作用(Eq. 24).
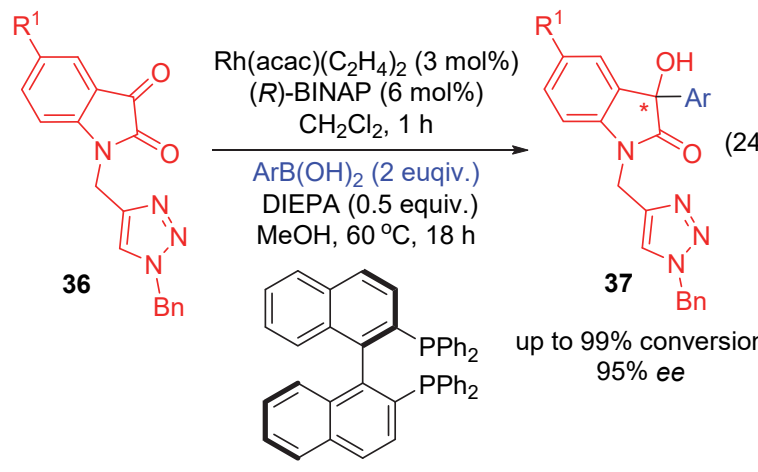

up to $99 \%$ conversion $95 \%$ ee

L21

\section{2 其他金属催化的靛红以及 2,3 -二酮苯并呋喃的不 对称芳基化}

2009 年, 秦勇课题组 ${ }^{[30]}$ 发展了一类手性四取代的 联苯磷亚胺配体 $\mathbf{L 2 2}$, 并将其用于靛红的不对称芳基化 的尝试. 当使用 $\mathrm{Rh}\left(\mathrm{CH}_{3} \mathrm{CN}\right)(\mathrm{cod}) \mathrm{BF}_{4}$ 或者 $\mathrm{Rh}_{2}(\mathrm{OAc})_{4}$ 作 为催化剂时, 由于存在严重的背景反应, 得到的都是消 旋的产物. 而使用 $\mathrm{Pd}(\mathrm{OAc})_{2}$ 作为催化剂时, 反应能以中 等的收率以及 $e e$ 值得到产物, 实验结果证明反应的立 体选择性主要是通过联苯的轴手性而不是通过磺酰亚 胺的硫手性来控制的. 此外他们还发现在反应体系中加 入 $\mathrm{BF}_{3} \cdot \mathrm{Et}_{2} \mathrm{O}$ 有助于反应收率的提高(Eq. 25).

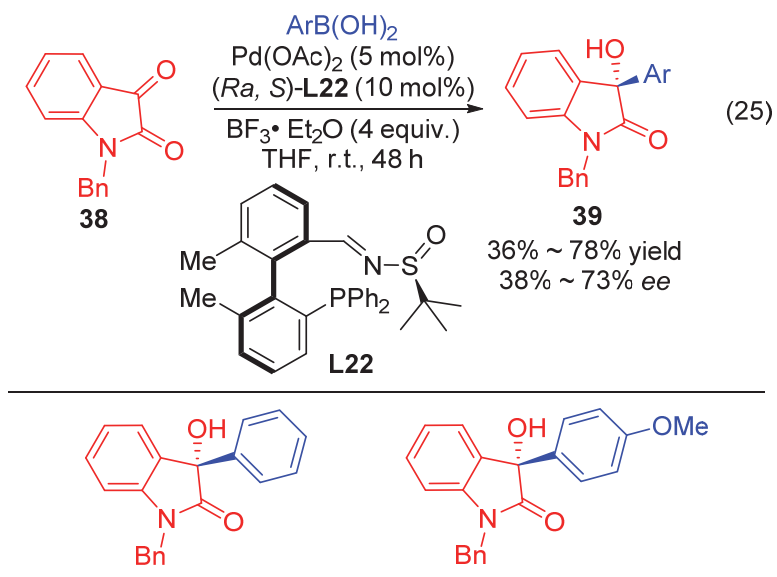

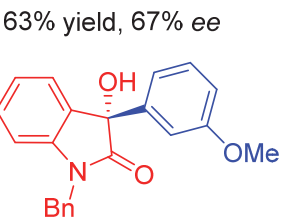

$51 \%$ yield, $73 \%$ ee
$78 \%$ yield, $38 \%$ ee

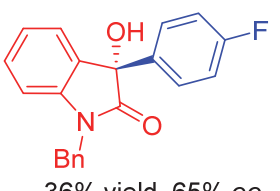

2011 年, Shi 和 $\mathrm{Li}$ 等 ${ }^{[31]}$ 报道了 $\mathrm{Pd}-\mathrm{NHC}$ 物种催化的 芳基嗍酸对靛红的不对称加成，反应可以获得 79\% 94\%收率以及中等偏上的对映选择性(Eq. 26). 在反应 
优化过程中他们发现碱的影响比较大, $\mathrm{LiOH} \cdot \mathrm{H}_{2} \mathrm{O}$ 作为 碱时, 无论是收率还是对映选择性都明显优于其他碱, 在反应机理考察的过程中, 他们认为加入的 $\mathrm{LiOH} \cdot \mathrm{H}_{2} \mathrm{O}$ 可以与芳基醇原位生成硬的 Lewis 酸 LiOAr, 生成的 $\mathrm{LiOAr}$ 与底物中两个羰基氧作用, 从而可以活化底物提 高反应收率(Scheme 4).

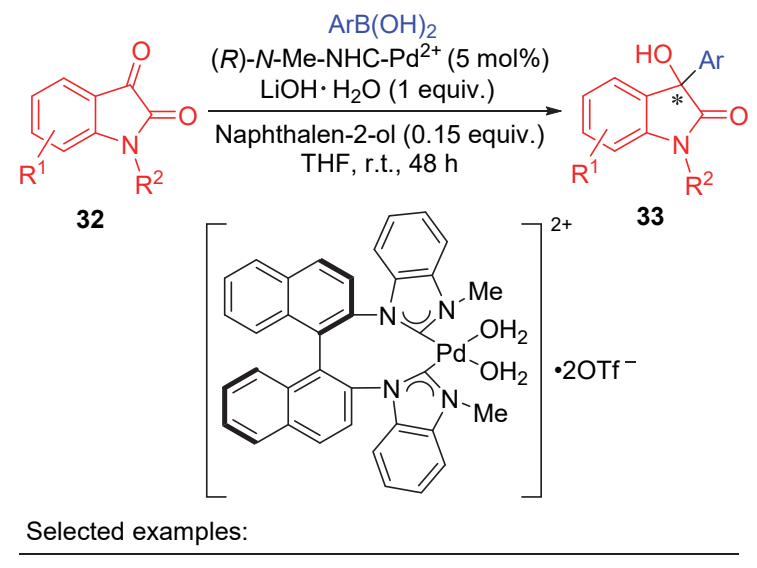

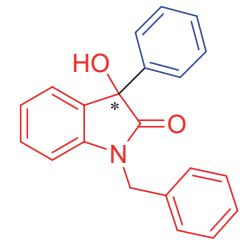

$94 \%$ yield, $94 \%$ ee

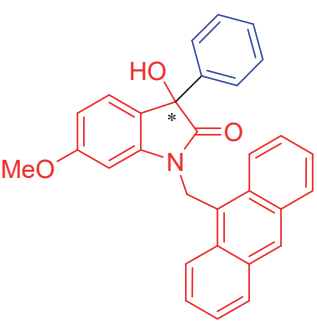

$91 \%$ yield, $60 \%$ ee

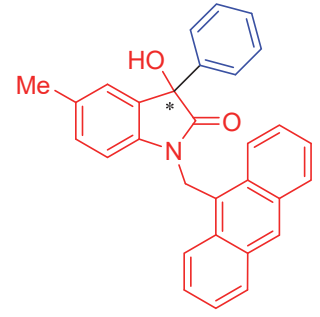

$91 \%$ yield, $80 \%$ ee

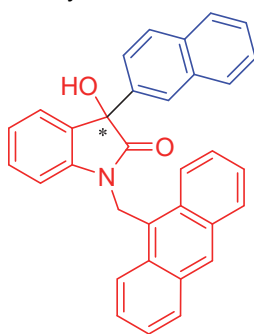

$91 \%$ yield, $65 \%$ ee
2013 年, Zhou 课题组 ${ }^{[32]}$ 利用基于 $\mathrm{H}_{8}$-BINOL 骨架的 膦噁唑啉配体 L23 同样实现了钯催化的芳基硼酸对靛 红的不对称加成, 取得最高 $88 \% \mathrm{ee}$ 值的产物, 其中 $\mathrm{H}_{8}$-BINOL 骨架和腎唑啉的手性匹配可以提高反应的收 率以及立体选择性, 同时此骨架的大位阻有利于反应的 立体选择性控制(Eq. 27).

Yamamoto 小组将发展的手性亚磷酰胺配体

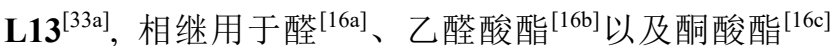
的不对称芳基化后, 又成功地将其用于钉催化的芳基硼 酸对静红的不对称加成中, 也可以取得不错的结果(Eq. 28). 反应机理被认为与铑催化的 1,2-加成类似，也是经 历了转金属化、芳基钓物种对不饱和键插入, 然后再水 解得到产物的过程.

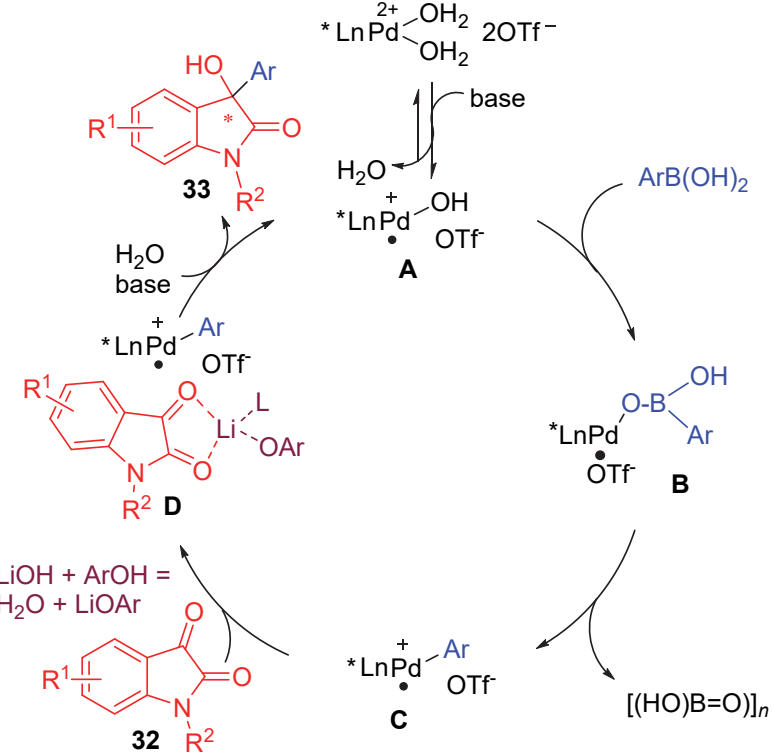

图式 4 推测的反应机理 Scheme 4 Proposed catalytic cycle
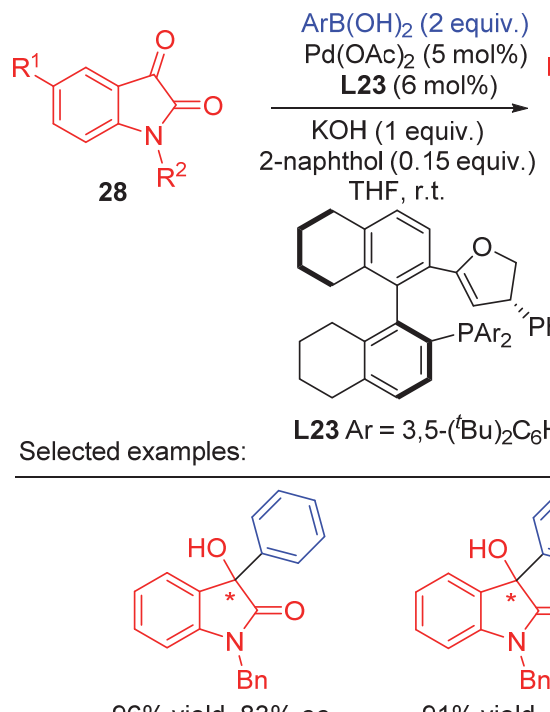

THF, r.t.

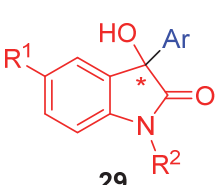

Selected examples:

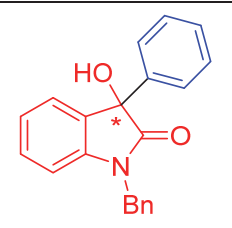

$96 \%$ yield, $83 \%$ ee

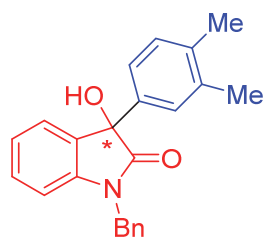

$87 \%$ yield, $88 \%$ ee

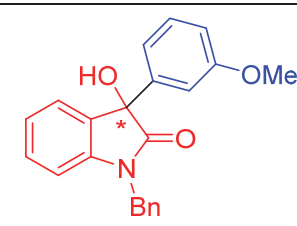

$91 \%$ yield, $73 \%$ ee

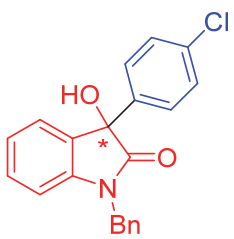

$85 \%$ yield, $80 \%$ ee
之后，该小组 ${ }^{[33 b]}$ 又利用相同的催化剂实现了 $2,3-$ 二酮苯并呋喃底物 $\mathbf{4 2}$ 的不对称芳基化, 添加的乙腈对 于反应收率非常重要，被认为可以防止二酮的两个羰基 毒化催化剂. 从反应结果来看, 底物中的 4 位甲基的存 在对反应收率和 $e e$ 值都有非常重要的影响, 这是因为 4 位甲基位阻的存在可以防止底物的水解同时提高反应 的立体选择性(Eq. 29). 


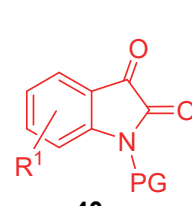

40

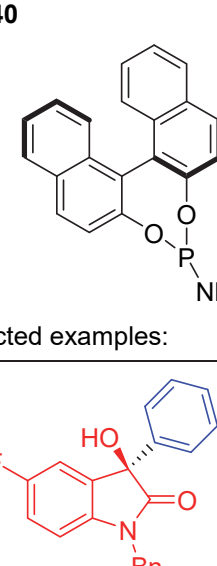

$\mathrm{Bn}$

95\% yield, $90 \%$ ee<smiles>Cc1cccc([C@]2(O)C(=O)N(C)c3ccc(Cl)cc32)c1</smiles>

$\mathrm{Bn}$

$99 \%$ yield, $87 \%$ ee
$\operatorname{ArB}(\mathrm{OH})_{2}$

$\left[\mathrm{RuCl}_{2}\left(\mathrm{PPh}_{3}\right)_{3}\right](2 \mathrm{~mol} \%)$

$\underset{(R, R)-\mathrm{Me}-\mathrm{BIPAM}(2.2 \mathrm{~mol} \%)}{\longrightarrow}$

toluene/ $/ \mathrm{H}_{2} \mathrm{O}(\mathrm{V}: \mathrm{V}=10: 1)$

$50{ }^{\circ} \mathrm{C}, 24 \mathrm{~h}$

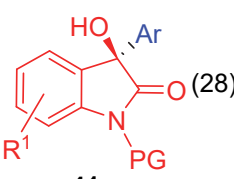

41
$51 \% \sim 99 \%$ yield $46 \% \sim 90 \%$ ee

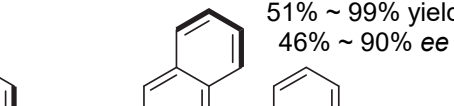

L13

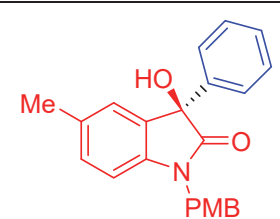

95\% yield, $90 \%$ ee

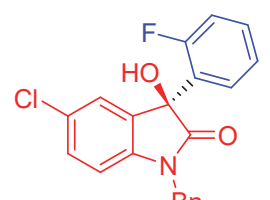

$\mathrm{Bn}$

$\operatorname{ArB}(\mathrm{OH})_{2}$

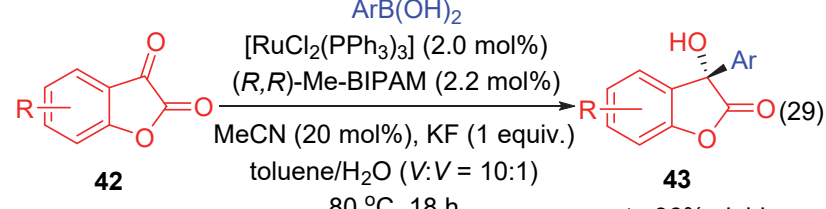

$80^{\circ} \mathrm{C}, 18 \mathrm{~h} \quad$ up to $96 \%$ yield

Selected examples:

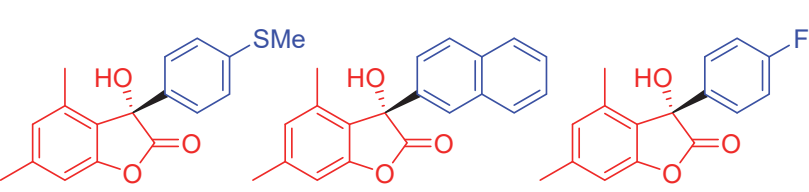

$75 \%$ yield, $90 \%$ ee $\quad 86 \%$ yield, $96 \%$ ee

$96 \%$ yield, $94 \%$ ee

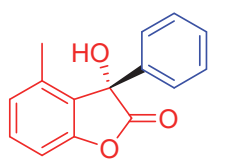

$68 \%$ yield, $92 \%$ ee

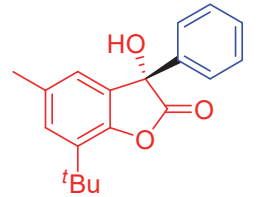

$46 \%$ yield, $2 \%$ ee

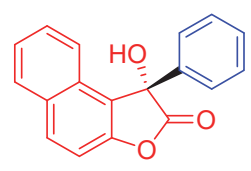

$64 \%$ yield, $5 \%$ ee

2010 年, Hayashi 和 Shintani 等 ${ }^{[34]}$ 共同报道了 $\mathrm{Cu}$ / $\mathrm{NHC}$ 催化的芳基硼酸酯对靛红的不对称加成, 反应能 以中等到优异的收率得到 $e e$ 值为 $67 \% \sim 92 \%$ 的产物(Eq. 30). 他们通过实验证明, 反应可能经历了与铑催化的 反应相似的过程: 氯化铜与卡宾 L 24 形成反应的活性成 分叔丁醇氧 $\mathrm{N}$-杂环卡宾铜, 然后与硼酸酯发生转金属 化后形成芳基铜物种, 该物种再与底物反应形成烷氧基

铜中间体，此中间体与叔丁醇钾生成活性的叔丁醇氧 $\mathrm{N}$-杂环卡宾铜进入下一个循环同时释放出产物, 这样一 个反应循环也可以在一定程度上解释添加剂叔丁醇钾 的重要性(Scheme 5).

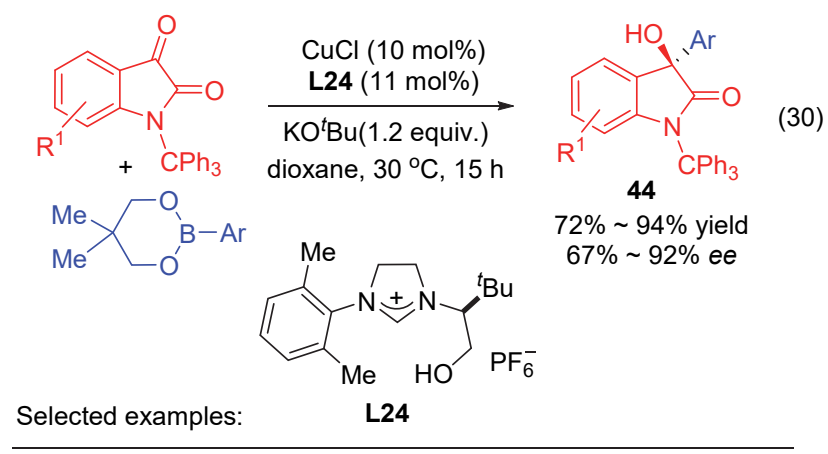

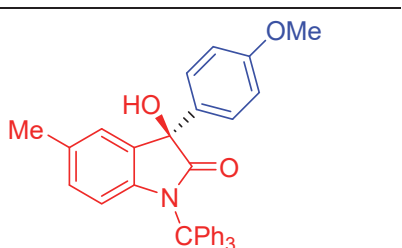

$67 \%$ yield, $85 \%$ ee

$87 \%$ yield, $92 \%$ ee<smiles>COc1ccc([C@]2(O)C(=O)N(c3ccccc3)c3ccccc32)cc1</smiles>

$80 \%$ yield, $88 \%$ ee

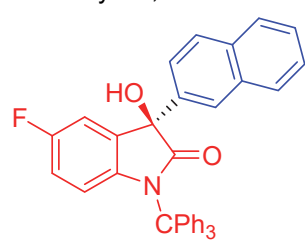

$74 \%$ yield, $68 \%$ ee

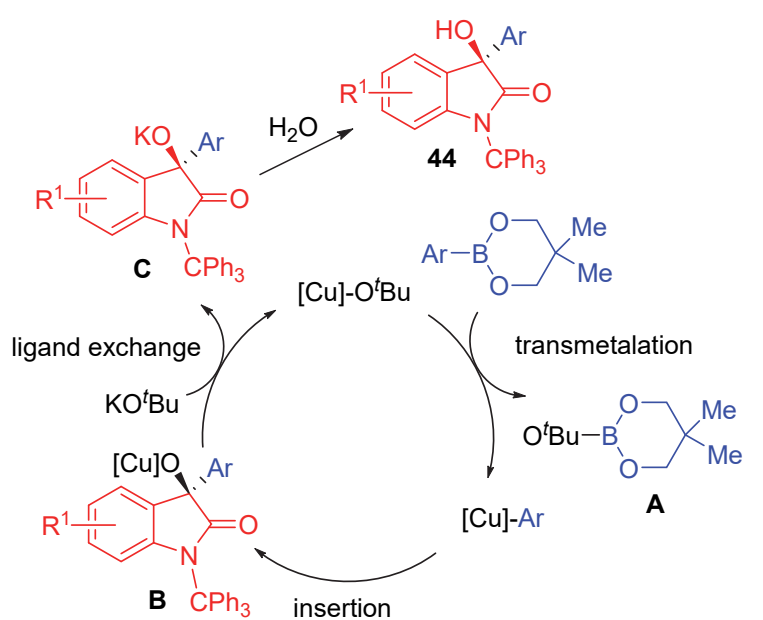

图式 5 推测的反应机理

Scheme 5 Proposed catalytic cycle

2015 年, Qiu 等 ${ }^{[35]}$ 报道了基于手性桥环联苯骨架的 手性亚磷酰胺配体, 并将其用于铱催化的芳基硼酸对靛 红的不对称加成反应之中, 以中等到优异的收率得到 $e e$ 值为 76\% 95\%的手性的 3-芳基-3-羊基-2-吲哚酮产物. 他们在实验中发现, 配体中比较拥挤的环境不仅有利于 促进反应的进行从而提高反应收率，而且也有助于反应 
的立体选择性控制(Eq. 31).

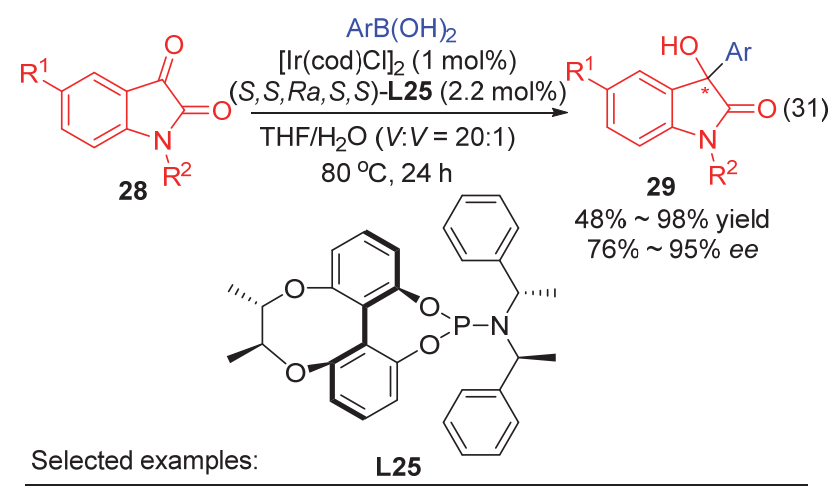

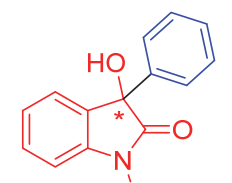

$\mathrm{Bn}$

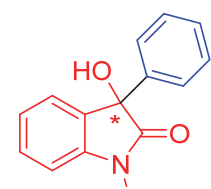

$\mathrm{Tr}$

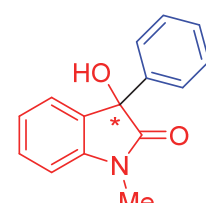

Me
$98 \%$ yield, $93 \%$ ee $\quad 19 \%$ yield, $41 \%$ ee $\quad 58 \%$ yield, $67 \%$ ee
$50 \%$ yield, $76 \%$ ee<smiles>O=C1N(Cc2ccccc2)c2ccc(Cl)cc2C1(O)c1ccccc1</smiles><smiles>O=C1N(Cc2ccccc2)c2ccccc2C1(O)c1ccc(F)c(F)c1</smiles>

$85 \%$ yield, $95 \%$ ee

\section{3 酮酸酯的不对称芳基化}

手性 2-羟基二芳基乙酸酯是合成毒蕈碱受体拮抗 剂的关键中间体 ${ }^{[36]}$, 芳基喼酸对芳基酮酸酯进行 1,2-加 成便可以直接构建此类分子骨架, 但是反应的立体选择 性通常难以控制，因此寻找合适的反应体系至关重要. 近年来各种不同的反应体系也被成功发展并用于该类 化合物的构建之中.

2008 年, 周其林课题组 ${ }^{[37]}$ 利用他们发展的螺环的 亚磷酸酯配体, 首次实现了 $\mathrm{Rh}(\mathrm{I})$ 催化的芳基硼酸对 $\alpha$ 酮酸酯的不对称 1,2-加成, 反应可以取得中等到优异的 对映选择性. 他们认为加入的 $\mathrm{LiF}$ 不仅仅作为碱, 其中 的氟离子也可以和芳基嗍酸中的嗍络合加速芳基铑物 种的形成, 从而有利于反应收率的提高. 利用该催化体 系，他们还选择性地实现了同时具有 1,2-和 1,4-加成反 应位点的 $\alpha, \beta$-不饱和酮酸酯的不对称 1,2-加成(Eq. 32).

2011 年, Ready 等 ${ }^{[38]}$ 设计合成了手性联烯骨架的双 膦配体，并将其用于 $\mathrm{Rh}(\mathrm{I})$ 催化的芳基硼酸对芳基酮酸 酯的不对称加成反应之中，在温和的条件下可以以 $52 \% \sim 98 \%$ 收率得到 $72 \% \sim 95 \%$ ee 的产物. 络合物单晶 结构表明, 配体中两个磷以及联烯中的一个双键以三齿 配体的方式和铑配位. 两个磷原子上连有强吸电子的 3,5-二三氟甲基苯基的配体的活性最好, 可能的原因是

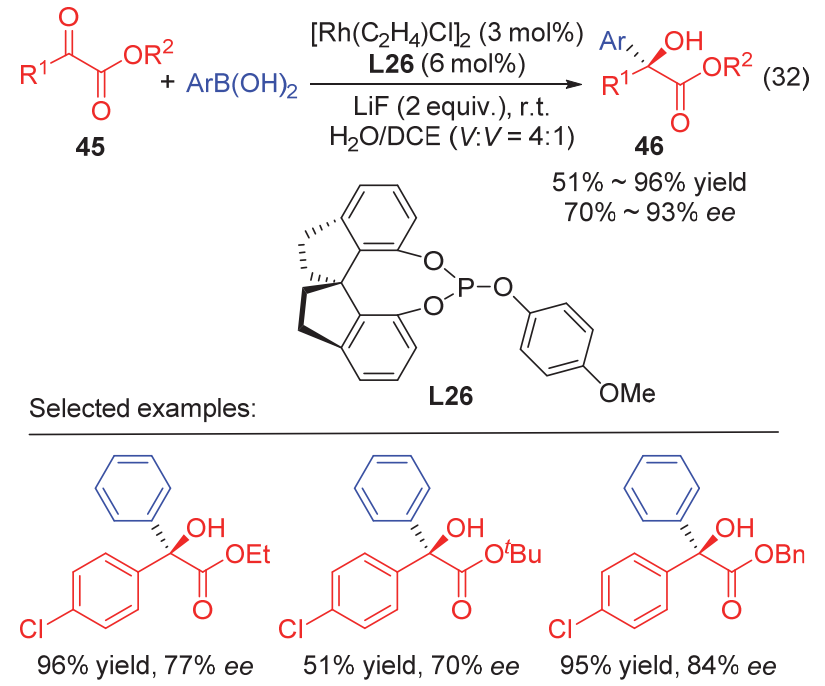

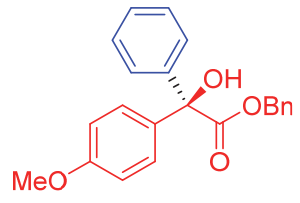

$93 \%$ yield, $86 \%$ ee

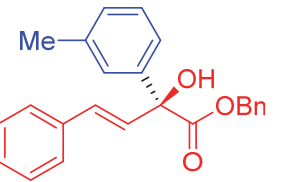

$75 \%$ yield, $91 \%$ ee

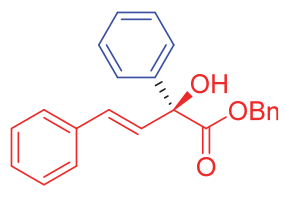

$70 \%$ yield, $93 \%$ ee

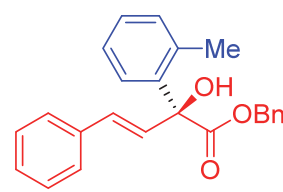

$92 \%$ yield, $75 \%$ ee
催化剂与底物络合后通过诱导效应，可有效减弱反应底 物的电负性，使得反应更易进行(Eq. 33).

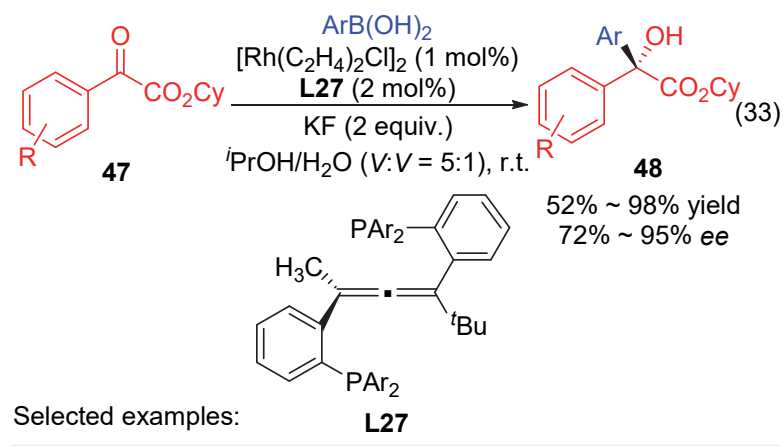

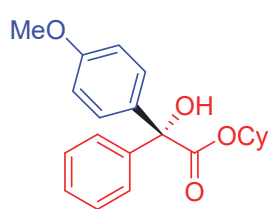

$90 \%$ yield, $91 \%$ ee

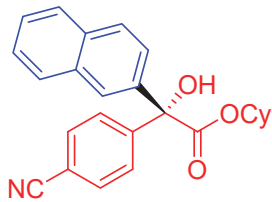

$87 \%$ yield, $92 \%$ ee

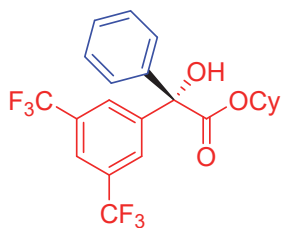

$89 \%$ yield, $91 \%$ ee

$\mathrm{MeO}$<smiles>CCCCCCCCCCCCOC(=O)[C@](O)(c1ccc(C)cc1)c1ccc(OC)cc1</smiles>

$81 \%$ yield, $84 \%$ ee 
几乎同时, 徐明华课题组 ${ }^{[39 a]}$ 报道了一类铑/手性硫 烯配体催化的芳基硼酸对 $\alpha$-芳基酮酸酯的不对称 1,2-加 成, 也取得了很好的结果, 其中手性硫烯配体 $\mathbf{L 2 8}$ 结构 极其简单，合成简便. 该催化体系被进一步拓展到 3-吲 哚- $\alpha$-酮酸酯的不对称 1,2-加成之中, 反应也表现出了很 好的底物适应性 ${ }^{[39 b]}$, 此外, 对于苯并呋喃以及苯并噻吩 取代的酮酸酯, 都能给出非常好的收率和对映选择性, 与芳香杂环的 Friedel-Crafts 反应相比, 该方法受底物的 电子效应影响较小, 为含芳香杂环季碳手性中心的 $\alpha$-羟 基羰基化合物的合成提供了新方法(Eq. 34).
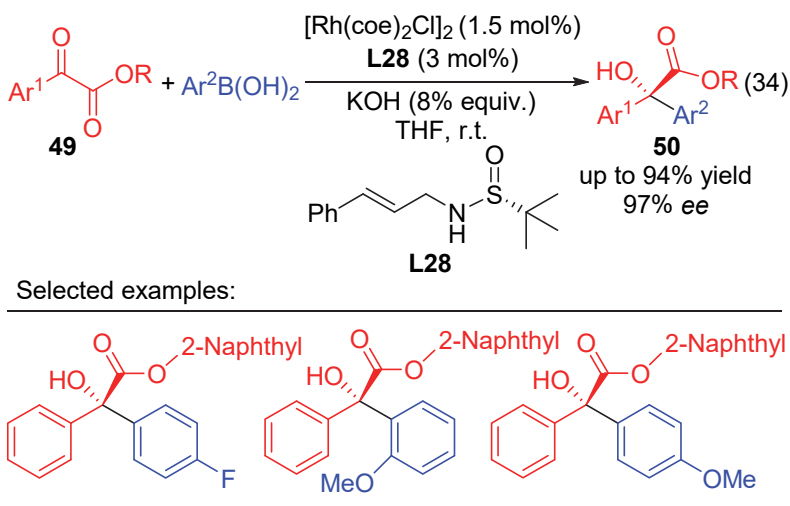

$86 \%$ yield, $94 \%$ ee $\quad 73 \%$ yield, $90 \%$ ee $\quad 94 \%$ yield, $92 \%$ ee<smiles>CCOC(=O)C(O)(c1cccc(Cl)c1)c1cn(C(=O)OC(C)(C)C)c2ccccc12</smiles>
$89 \%$ yield, $91 \%$ ee $\quad 80 \%$ yield, $97 \%$ ee $\quad 70 \%$ yield, $95 \%$ ee<smiles>CCOC(=O)[C@](O)(c1ccc(OC)cc1)c1cn(CC(C)(C)C)c2c(C)cccc12</smiles><smiles>CCOC(=O)[C@](O)(c1ccc(OC)cc1)c1c(C)n(-c2ccccc2)c2ccccc12</smiles>

通过在酮酸酯芳基邻位引入取代基团，徐明华小 组 ${ }^{[40]}$ 又成功实现了以不同取代的直链手性硫烯 L29 和

L30 为配体的 $\mathrm{Rh}(\mathrm{I})$ 催化的芳基硼酸对邻位官能团化的 芳基酮酸酯 51 的不对称 1,2-加成, 并进一步通过后续分 子内的环化反应高效构建了一系列含季碳手性中心的 高光学活性的苯并二氢异呋喃 52、3-芳基-3-羟基吲哚酮 53 和异色满-3-酮类化合物 $\mathbf{5 4}$ (Scheme 6).

$\alpha$-烷基取代的酩酸酯的不对称 1,2-加成非常挑战, 一直没有成功的报道. 2013 年, 徐明华小组 ${ }^{[4]}{ }^{14}$ 研究发现, 以手性硫烯为配体, 反应可以取得中等选择性. 有意思 的是，仅仅改变取代基在配体双键上的位置，反应得到 的产物的构型便发生了翻转, 直链配体 $\mathbf{L 2 8}$ 得到 $(S)$ 构 型产物 56, 而支链配体 $\mathbf{L 3 1}$ 得到 $(R)$ 构型产物 $\mathbf{5 7}$, 而以 $\alpha, \beta$-不饱和酮酸酯 $\mathbf{5 8}$ 为底物时, 发现支链配体主要得到

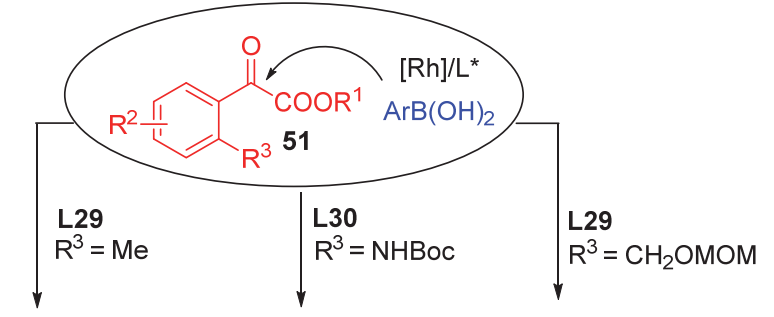

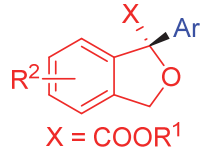

52

up to $98 \%$ ee

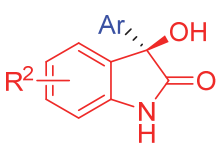

53 up to $96 \%$ ee

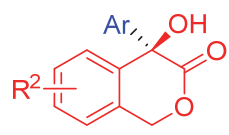

54 up to $88 \%$ ee<smiles>CC(C)(C)S(=O)NC/C=C/c1ccc(F)c(F)c1</smiles><smiles>CC(C)(C)/C=C/CNS(=O)C(C)(C)C</smiles>

图式 6 不对称芳基加成-环化策略制备手性杂环 Scheme 6 Asymmetric arylation-cyclization strategy for the synthesis of chiral heterocycles

1,2-加成的 $(R)$ 构型产物 $\mathbf{6 0}$, 而直链配体倾向于得到 1,4加成产物 59 (Scheme 7).
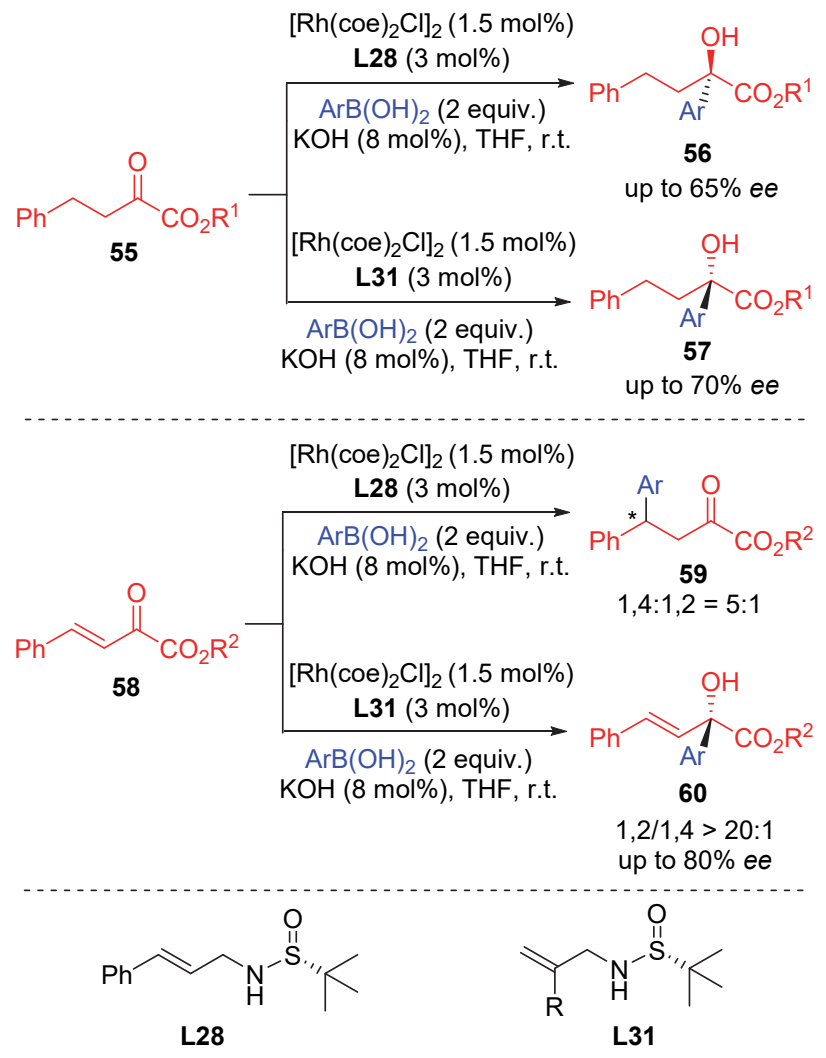

图式 7 配体调控的不对称芳基化

Scheme 7 Ligand-controlled asymmetric arylation

2018 年, Strand 等 ${ }^{[42]}$ 发展了一类基于面手性的二苯 并环辛二烯配体，他们通过在该类化合物的 5,11 位引入 
取代基，可以在一定程度上阻止其构象翻转，从而得到 手性配体. 这类配体在芳基硼酸对酮酸酯的不对称加成 反应中表现出较好的立体选择性控制, 可以取得最高 $94 \%$ ee 值的结果(Eq. 35).
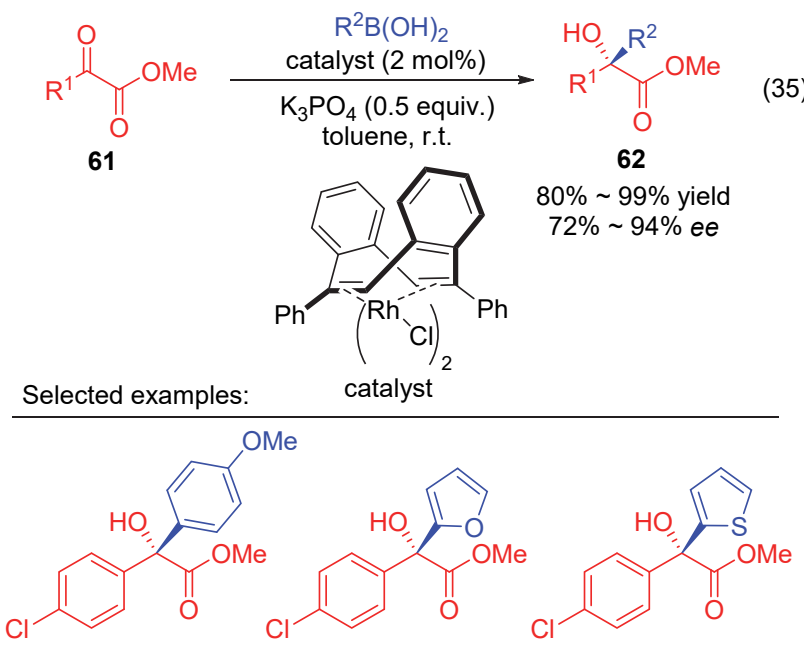

$99 \%$ yield, $89 \%$ ee $\quad 80 \%$ yield, $94 \%$ ee $\quad 81 \%$ yield, $90 \%$ ee

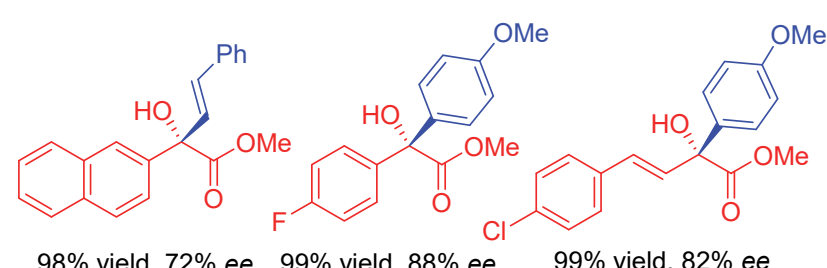

$98 \%$ yield, $72 \%$ ee $\quad 99 \%$ yield, $88 \%$ ee $\quad 99 \%$ yield, $82 \%$ ee

最近, $\mathrm{Wu}$ 小组 ${ }^{[43]}$ 以[2.2.1]庚二烯骨架的手性双烯 $\mathbf{L 3 2}$ 为配体也实现了铑催化的芳基嗍酸对酮酸酯的不对 称加成, 取得最高 $99 \%$ ee 值的结果(Eq. 36). 该反应体 系表现出较高的催化活性，在催化剂的量为 $0.5 \mathrm{~mol} \%$ 时, 反应也能给出较高的收率. 利用该方法, 以产物 63 为原料, 经 3 步反应高效实现了具有抗真菌活性的脱甲 基抑制剂(S)-flutriafol 的对映选择性合成(Scheme 8).

2017 年, Johnson 小组 ${ }^{[44]}$ 以 Rh(I)/手性双烯 $\mathbf{L 3 3}$ 和 L34 催化的芳基硼酸对酮酸酯的不对称加成为基础, 实 现了 $\beta$ 位取代的 $\alpha$-酮酸酯 66 的动态动力学拆分, 反应 可以实现非常优异的非对映选择性以及对映选择性的 控制. 反应结果表明有机碱在反应的对映选择性的控制 中起着非常关键的作用, 这是因为有机碱可以影响 $\beta$ 取 代基的消旋化速度(Eq. 37).

\section{4 铑催化的二酮的不对称芳基化}

光学活性的 $\alpha$-羟基酮是许多生物活性分子的重要 结构单元, 如烟酸受体激动剂呋喃酸 ${ }^{[45]}$ 与人体免疫缺 损病毒(HIV)整合酶抑制剂 Integrastatin ${ }^{[46]}$. 偶酰类二酮 化合物的不对称加成是制备此类化合物的直接方法, 但 由于底物中同时存在两个羰基, 反应的选择性通常难以 控制, 通过相应的傅克反应或有机锡试剂加成来制备,

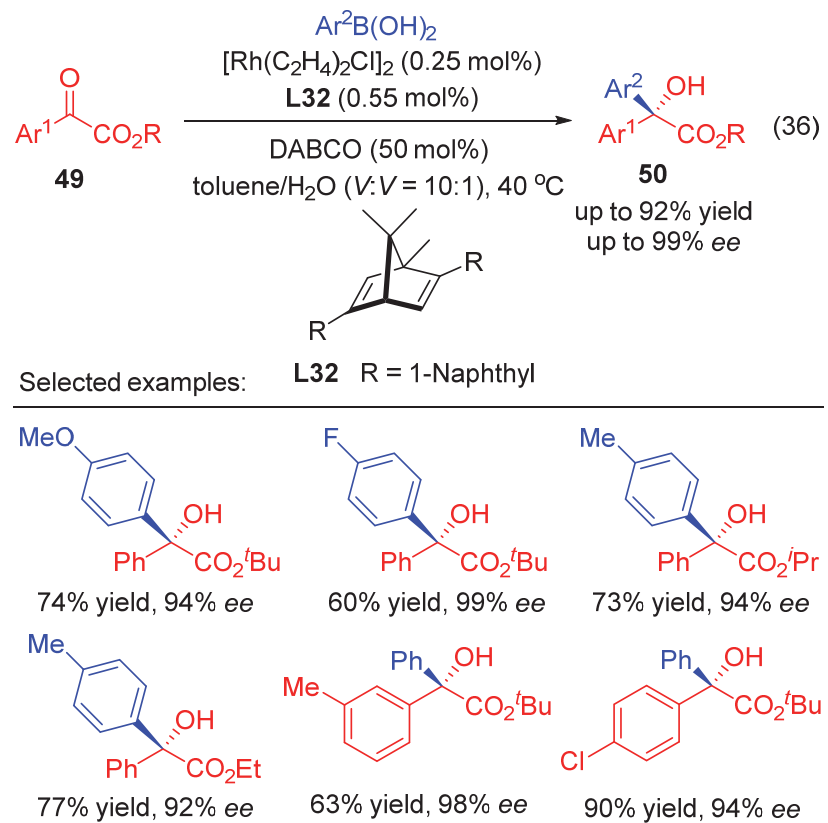<smiles>CC(C)(C)C(O)OC(=O)[C@](O)(c1ccccc1)c1ccc(C(F)(F)F)cc1</smiles>

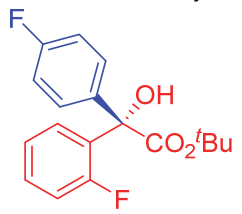

$99 \%$ yield, $91 \%$ ee

$57 \%$ yield, $98 \%$ ee

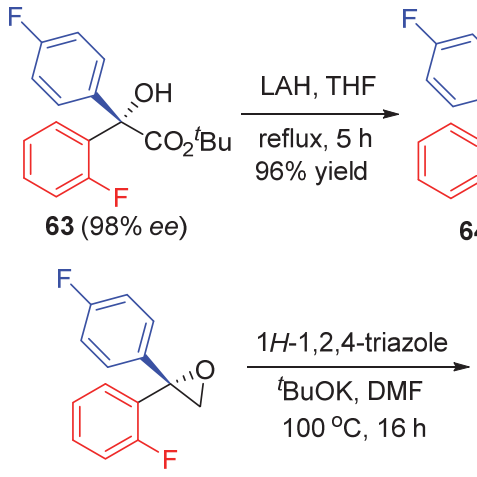

65

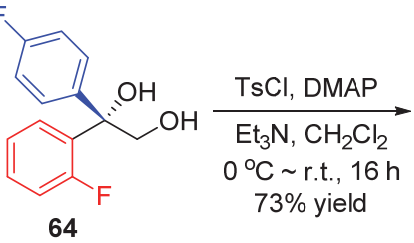

F<smiles>O[C@@](Cn1cncn1)(c1ccc(F)cc1)c1ccccc1F</smiles>

(S)-flutriafol $91 \%$ yield, $98 \%$ ee
图式 $8(S)$-Flutriafol 的对映选择性合成

Scheme 8 Asymmetric synthesis of $(S)$-flutriafol

又存在较大的底物局限性和锡试剂剧毒性的问题.

虽然芳基硼酸在对靛红、酮酸酯以及三氟甲基酮的 不对称加成中都取得了不错的结果, 但对邻二酮底物的 不对称芳基化却一直未见成功的例子报道. 直到 2012 年, 徐明华课题组 ${ }^{[39 a]}$ 利用铑/手性硫烯配体的催化体系 首次实现了邻二酮 68 的不对称芳基化，对于大部分的 二芳基邻二酮均可以取得大于 $95 \% \mathrm{ee}$ 值的结果，而且 对于更加挑战的甲基取代的烷基邻二酮，反应也能取得 中等的对映选择性(Eq. 38).

同年，杜海峰课题组 ${ }^{[47]}$ 也报道了将硫烯配体 $\mathbf{L 2 0}$ 用 于铑催化的邻二酮的不对称加成的例子，该反应体系对 

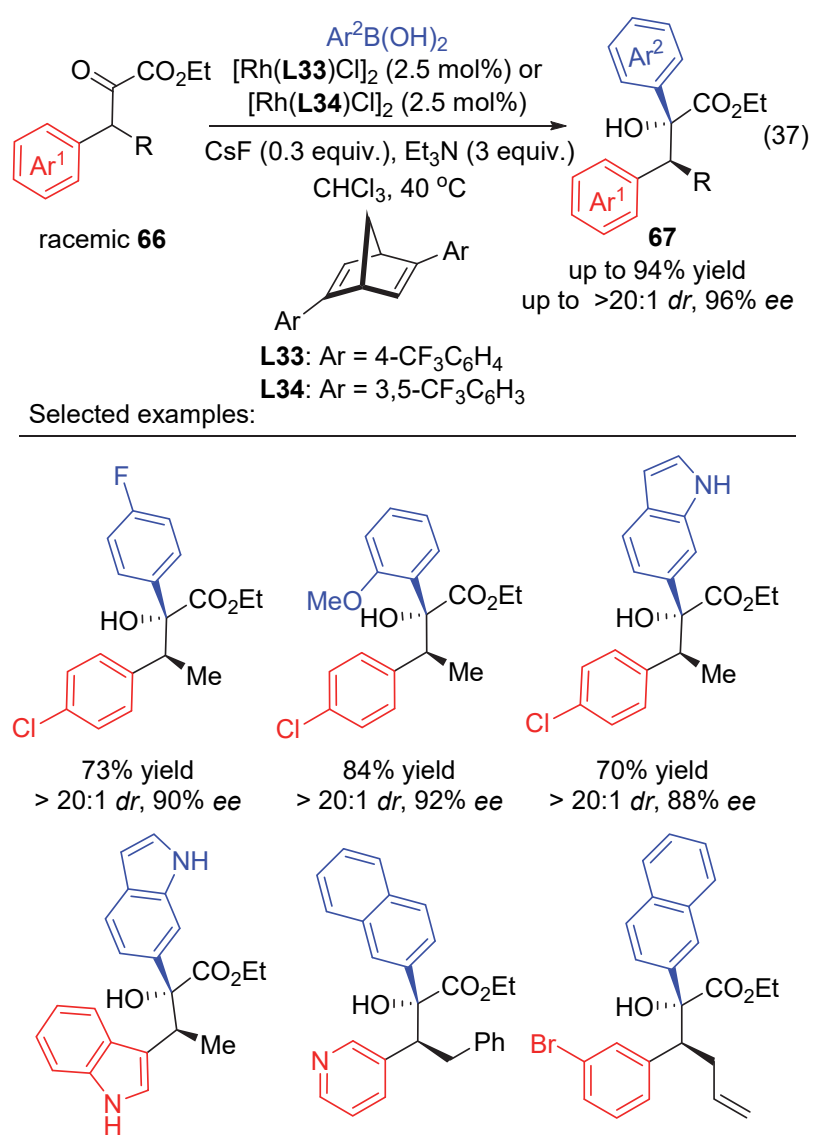

$84 \%$ yield
$>20: 1 d r, 92 \%$ ee
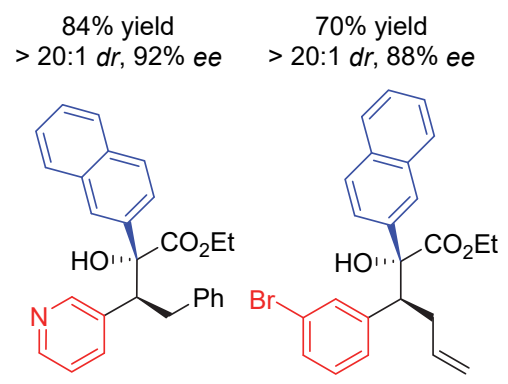

$71 \%$ yield
$>20: 1 d r, 92 \%$ ee

$67 \%$ yield
$>20: 1 d r, 96 \%$ ee

$47 \%$ yield

$\mathrm{ArB}(\mathrm{OH})_{2}$

$\mathrm{R}_{\mathrm{O}}^{1} \prod^{\mathrm{O}} \mathrm{R}^{2}$ $\underset{\mathrm{LOH}\left(0.1 \mathrm{~mol} \cdot \mathrm{L}^{-1}\right) / \mathrm{THF}, \text { r.t. }}{\stackrel{\left.\mathrm{Rh}(\mathrm{coe})_{2} \mathrm{Cl}\right]_{2}(1.5 \mathrm{~mol} \%)}{\mathrm{KO}(3.3 \mathrm{~mol} \%)}}$

68<smiles>CC(C)(C)S(=O)NC/C=C/c1ccccc1</smiles>

\section{L28}

Selected examples:

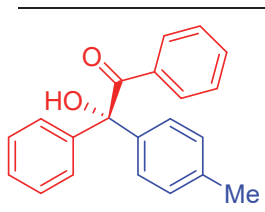

$97 \%$ yield, $97 \%$ ee
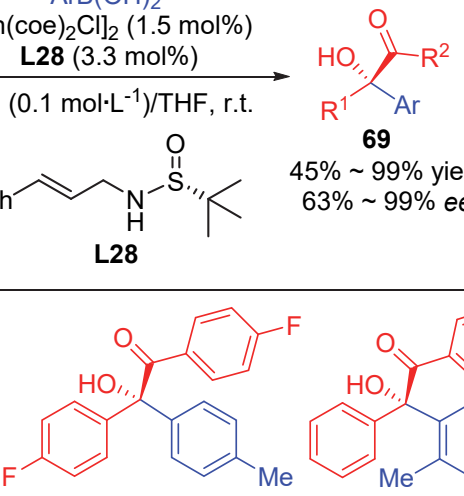

69

$45 \% \sim 99 \%$ yield $63 \% \sim 99 \%$ ee

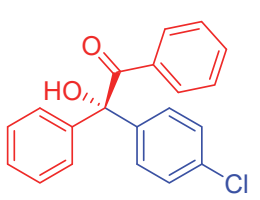

$97 \%$ yield, $99 \%$ ee

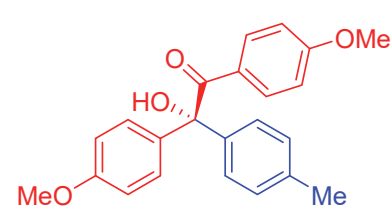

$98 \%$ yield, $97 \%$ ee

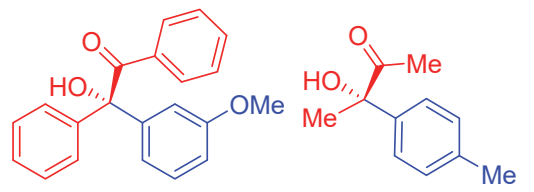

$95 \%$ yield, $97 \%$ ee $\quad 45 \%$ yield, $63 \%$ ee

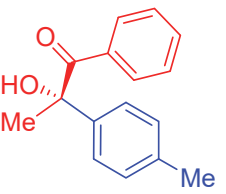

$85 \%$ yield, $80 \%$ ee

于环二芳基酮也能取得非常优异的收率和对映选择性, 但是对于含杂环的二酮底物, 反应的选择性并不理想 (Eq. 39).

$$
\text { (39) }
$$
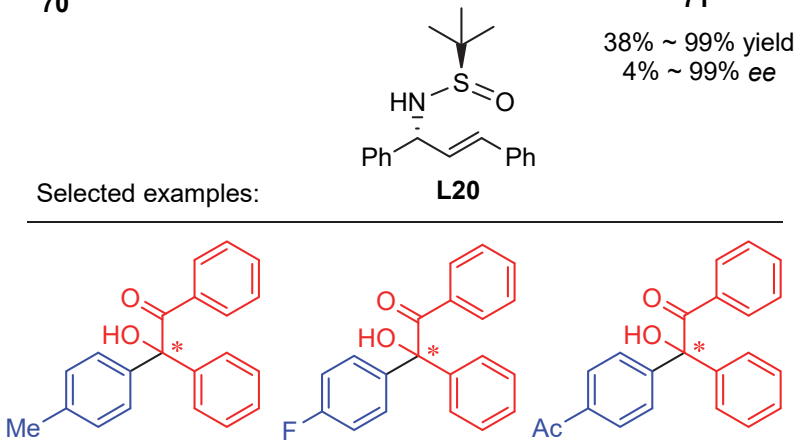

$88 \%$ yield, $98 \%$ ee $\quad 56 \%$ yield, $99 \%$ ee $\quad 61 \%$ yield, $99 \%$ ee<smiles>COc1ccc([C@](O)(C(=O)c2cccc(OC)c2)c2cccc(OC)c2)cc1</smiles>

$99 \%$ yield, $98 \%$ ee $\quad 40 \%$ yield, $88 \%$ ee $\quad 99 \%$ yield, $99 \%$ ee<smiles>COc1ccc(C(O)(C(=O)c2ccco2)c2ccco2)cc1</smiles>

$99 \%$ yield, $4 \%$ ee

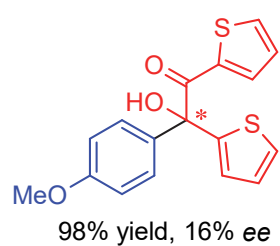

2016 年，曾庆乐等 ${ }^{[48]}$ 发展了一类环状亚磺酰胺结 构的手性硫烯配体 L35, 在铑催化的 4-甲氧基苯硼酸对 偶酰的不对称芳基加成反应中，可以取得 $90 \%$ 收率和 $90 \%$ ee 的结果(Eq. 40).

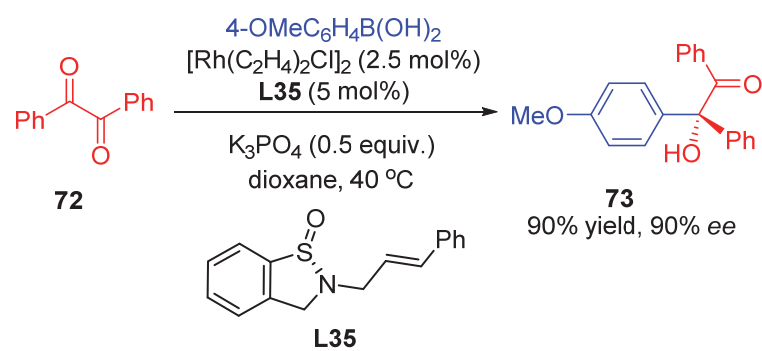

基于邻二芳基酮的不对称加成的优异结果，徐明华 小组 ${ }^{[49]}$ 又设计了在一侧酮的芳基邻位引入卤素或酯基, 利用位阻以及反应活性的差异实现对其中一个酮羰基 的选择性加成, 然后再串联分子内梄化环化或者酯化的 策略. 基于该策略, 成功地实现了一锅法合成高光学活 性的异色满 4-酮 74 以及异色满 1,4-二酮化合物 76 (Eqs. 
41, 42), 并进一步利用该方法, 以产物 78 为原料, 通过 两个线性步骤简单转化实现了 Urotensin-II 抑制剂 AC-7954 (80)的首次催化不对称合成, 该方法为手性异 色酮类药物的合成提供了高效的不对称合成途径 (Scheme 9).<smiles>[X]Cc1ccccc1C(=O)C(=O)CCc1ccccc1</smiles>

74 $\mathrm{X}=\mathrm{Cl}, \mathrm{Br}$ $\mathrm{ArB}(\mathrm{OH})_{2}$ $\left[\mathrm{Rh}(\mathrm{coe})_{2} \mathrm{Cl}\right]_{2}(1.5 \mathrm{~mol} \%)$

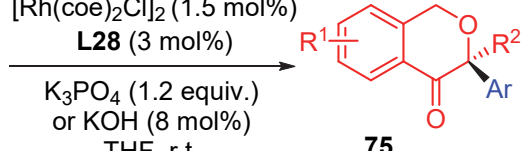<smiles>CC(C)(C)S(=O)NC/C=C/c1ccccc1</smiles>

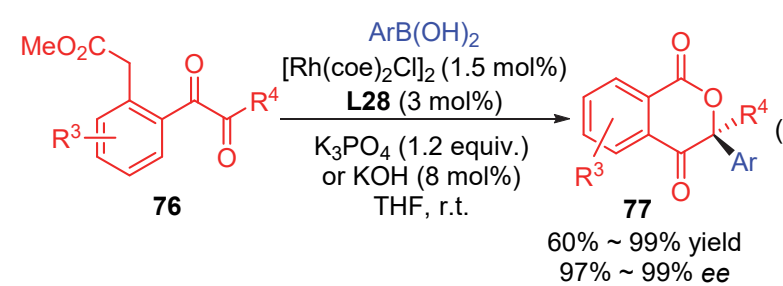

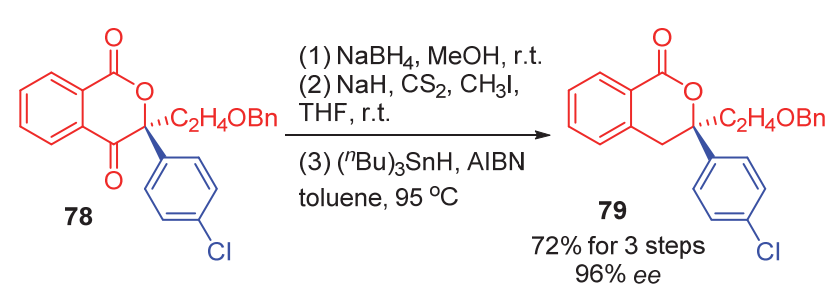

图式 9 AC-7954 的合成

Scheme 9 Synthesis of AC-7954

最近, 徐明华小组 ${ }^{[50]}$ 又设计了一类芳基邻位卤素 取代的邻二芳基酮底物 $\mathbf{8 1}$, 将铑催化的不对称芳基化 和钯催化的 $\mathrm{C}-\mathrm{O}$ 偶联进行组合, 通过双金属协同催化 的一锅法反应实现了偕二芳基取代的苯并呋喃酮 82 的 高对映选择性合成, 反应能以高收率取得优秀的对映选 择性(最高 $99 \%$ ee ). 值得一提的是, 该方法利用两种金 属催化反应的温度差异来实现反应的调控; 需要指出的 是, 底物中的卤素的选择也非常重要, 当为活性较高的 溴时，底物容易发生 Suzuki 偶联等副反应(Eq. 43).

此外, 徐明华小组 ${ }^{[51]}$ 还设计并合成了一类基于手 性 BINOL 骨架的开链磷烯配体 L36, 这类配体在铑催 化的芳基硼酸对邻二酮的不对称 1,2-加成中也表现出非 常优异的特性, 反应以非常优异的收率得到光学纯度高

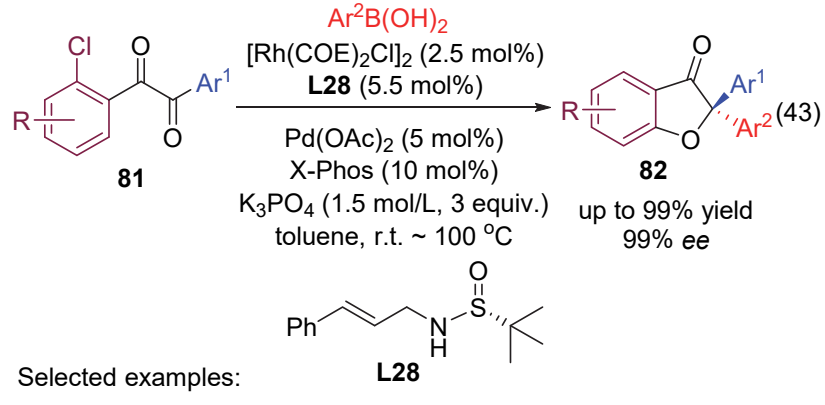<smiles>Cc1cccc([C@]2(c3ccccc3)Oc3ccccc3C2=O)c1</smiles>

$99 \%$ yield, $98 \%$ ee $\quad 85 \%$ yield, $98 \%$ ee $\quad 88 \%$ yield, $97 \%$ ee<smiles>COc1ccc([C@]2(c3ccc(C)cc3)Oc3ccccc3C2=O)cc1</smiles>

达 96\%的产物. 当将配体中的双键还原或者移去后反应 的立体选择性都出现大幅下降以及配体与铑配位的核 磁谱图数据均证实了该类配体是通过双键和磷与同时 铑配位而不是传统的只通过磷与铑配位的方式(Eq. 44).

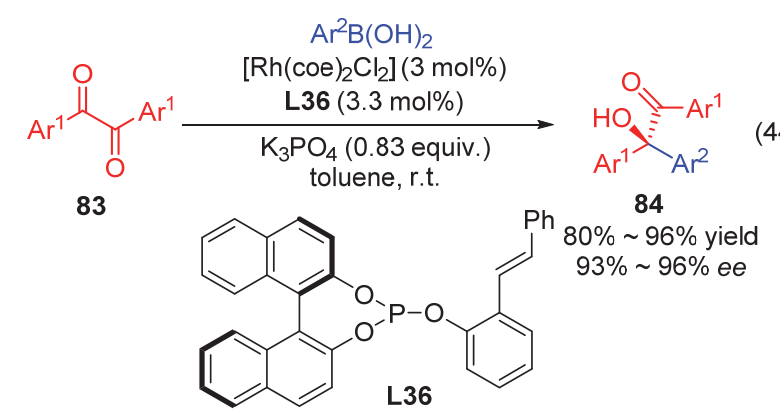

Selected examples:
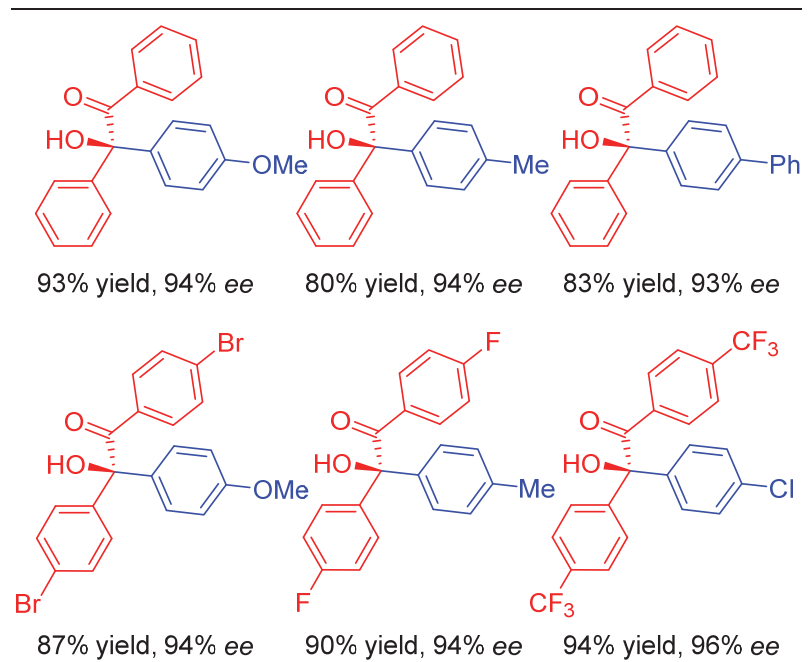


\section{5 三氟苯乙酮的不对称芳基化}

因为氟原子的引入不仅可以调节药物分子的理化 特性, 还可以提高药物的生物利用度以及代谢稳定 性 $^{[52]}$, 近年来含氟药物在临床治疗药物中占的比例越 来越大. 手性的三氟甲基叔醇类骨架由于其存在于一些 生物活性分子中而受到人们的关注, 酮的不对称三氟甲 基化是构建此类骨架的传统方法, 但是反应的立体选择 性通常难以控制.

2006 年, Minnaard 等 ${ }^{[53]}$ 利用铑/磷酰亚胺 L37 的催 化体系，实现了三氟苯乙酮类化合物 85 的不对称芳基 化，虽然底物的适应性不广，收率和对映选择性也还不 够理想, 但是这是首次通过铑催化的芳基硼酸对三氟甲 基酮的不对称加成来构建手性三氟甲基叔醇类化合物 的报道(Eq. 45).

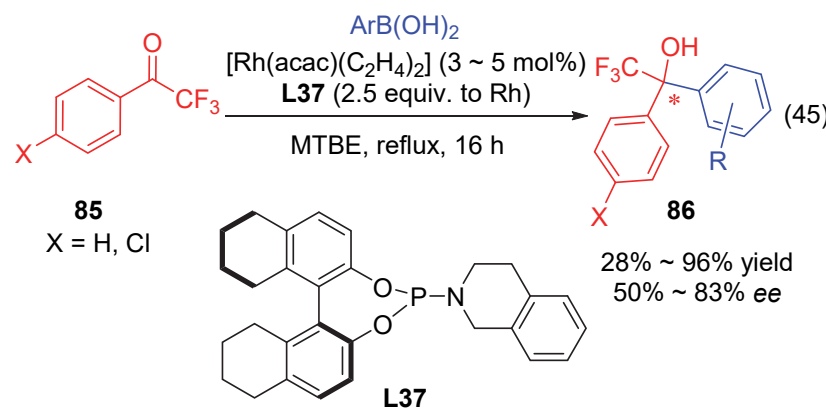

Selected examples:

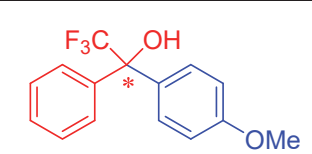

$50 \%$ yield, $68 \%$ ee

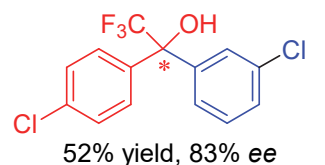

2010 年, Iuliano 等 ${ }^{[54]}$ 报道了以脱氧胆酸衍生物的亚 磷酸盐 L38 作为手性配体诱导芳基䃉酸对三氟苯乙酮 的不对称加成的例子，该体系具有较高的反应活性，即 使在常温条件下反应也能在短时间内给出 $70 \%$ $95 \%$ 的 收率，但是遗憾的是反应的底物适应性较窄而且选择性 较低(Eq. 46).

2013 年, 汤文军课题组 ${ }^{[55]}$ 发展了一类新型手性双 膦配体 L39，在铑催化的芳基硼酸对三氟苯乙酮的不对 称加成反应中取得很好的结果，该方法能够以最高 $93 \%$ 的产率以及最高 $99 \%$ ee 值得到加成产物, 并且该反应 体系表现较为广泛的底物适应性, 无论是杂环的还是邻 位取代的酮, 反应都能给出比较优异的结果. 通过 X-ray 单晶衍射确定了产物的绝对构型, 并结合产物的 立体化学对反应的过渡态进行了探讨(Eq. 47).
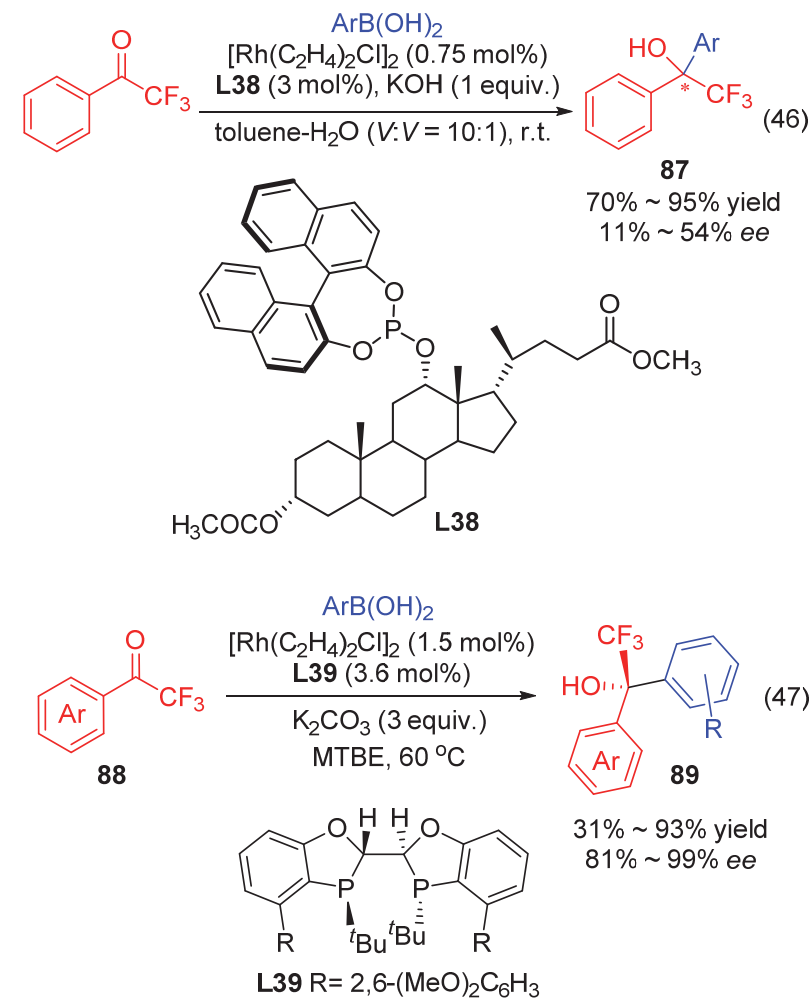

Selected examples:
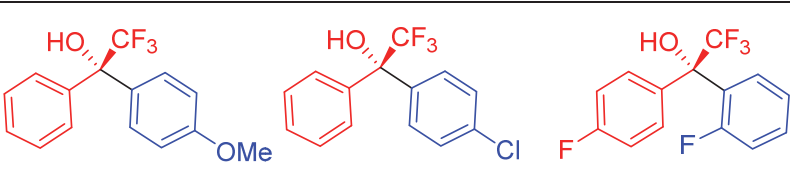

$79 \%$ yield, $95 \%$ ee

$83 \%$ yield, $97 \%$ ee

$73 \%$ yield, $99 \%$ ee<smiles>OC(c1ccc(Cl)cc1)(c1cccs1)C(F)(F)F</smiles>

$61 \%$ yield, $89 \%$ ee
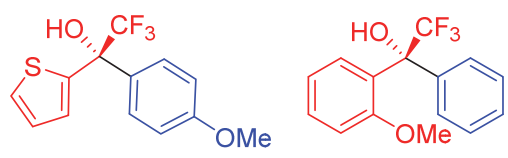

$81 \%$ yield, $81 \%$ ee

\section{6 过渡金属催化的非活泼酮的不对称芳基化}

相比活泼酩，非活泼酮的不对称芳基化相对更加困 难. 传统的方法主要是使用芳基锌试剂对其进行加成来 实现，考虑到芳基锌试剂的制备与稳定性的问题，芳基 硼酸对非活泼酮的不对称加成更加引起人们的兴趣，最 近这方面的工作也取得了一定的进展.

\section{1 铑催化的非活泼酮的不对称芳基化反应}

2011 年, Sakai 等 ${ }^{[56]}$ 在尝试了将双膦配体 BINAP (L21)用于铑催化的苯硼酸对 2-乙酰菜的不对称加成中, 虽然发现使用缺电子双膦配体与铑的络合物可以有效 活化反应底物, 进而得到高收率的加成产物, 但是反应 的对映选择性很不理想(Eq. 48).

2012 年, 胡桥生课题组 ${ }^{[57]}$ 将 [3.3.0]-辛二烯骨架的 手性双烯配体 L40 用于铑催化的芳基硼试剂对非活泼 酮的不对称芳基化中，反应能以优异的收率得到最高为 


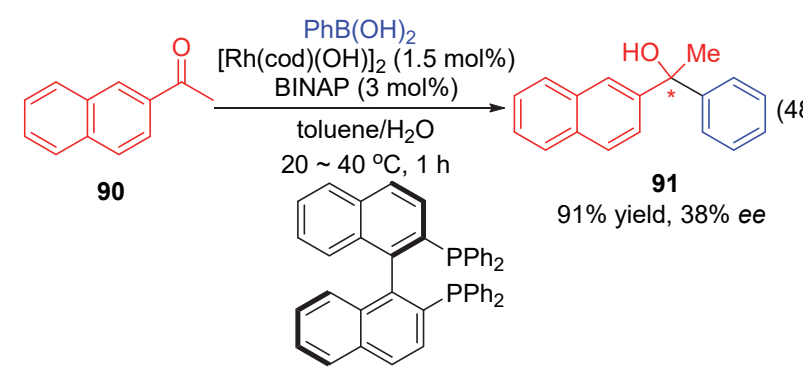

L21

$68 \% \mathrm{ee}$ 值的产物, 文中提到无水的反应体系对于催化 剂的活性保持至关重要(Eq. 49).
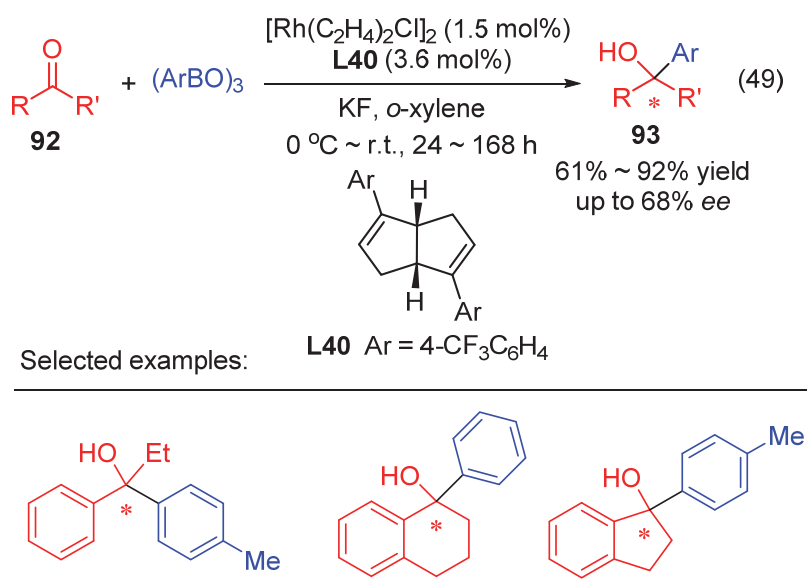

$83 \%$ yield, $47 \%$ ee

$81 \%$ yield, $36 \%$ ee

$83 \%$ yield, $56 \%$ ee

2016 年, 汤文军课题组 ${ }^{[58]}$ 在非活泼酮的不对称芳 基化研究方面取得突破, 他们以大位阻的双膦配体 WingPhos (L41)/铑作为催化剂, 硼䣶作为嗍源, 在体系 中加入澳化美帮助活化羰基, 实现了铑催化的芳基硼试 剂对简单酩的高效不对称加成, 构建了一系列高光学活 性的手性二芳基醇类化合物. 该反应体系解决了长期困 扰化学家们的简单酮的反应活性以及立体选择性不够 理想的问题(Eq. 50).

值得一提的是, 利用该方法可以实现两个手性药物 分子氯马斯汀和西酞普兰的合成. 以对氯苯乙酮 96 为 底物, 通过一步加成反应即可构建氯马斯汀的关键中间 体 97 (Scheme 10). 以 4-氯-(2,4-二氯苯基)-1-丁酮 98 为 反应底物, 利用 4-氟苯嗍䣶在铑催化条件下进行不对称 加成即可构建相应的季碳手性中心, 然后将得到的叔醇 化合物 99 与二甲胺盐酸盐反应引入 $N, N$-二甲基, 再经 钯催化双氧化引入氧基后, 其中一个㲵基再内酯化关 环，最后将内酯的羰基还原得到药物分子西酞普兰 101 (Scheme 11).

\section{2 镍催化的非活泼酮的不对称芳基化反应}

2009 年, Itami 课题组 ${ }^{[59]}$ 报道了零价镍/卡宾配体 L42 催化的芳基硼酸酯对非活泼酮的分子间加成，该方
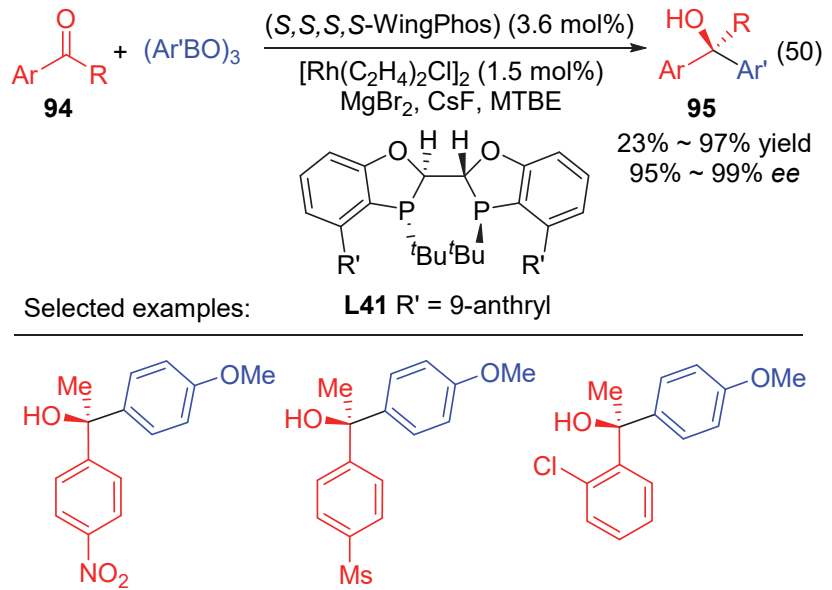

95\% yield, $99 \%$ ee $\quad 93 \%$ yield, $99 \%$ ee $\quad 45 \%$ yield, $98 \%$ ee

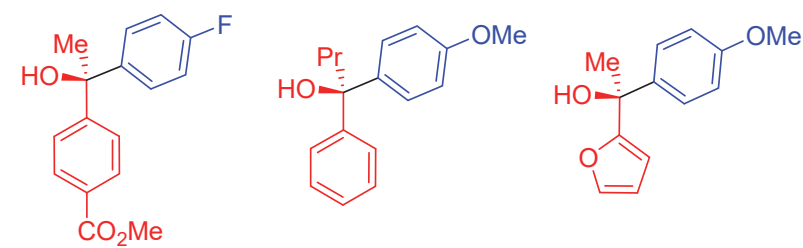

$95 \%$ yield, $99 \%$ ee $\quad 77 \%$ yield, $99 \%$ ee $\quad 80 \%$ yield, $95 \%$ ee

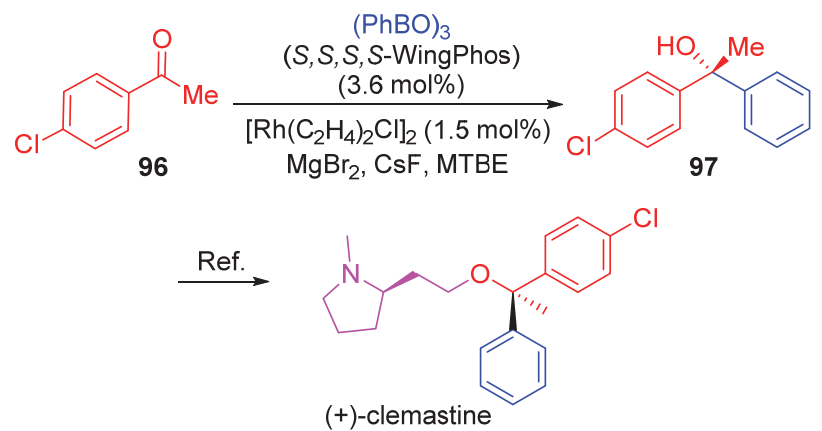

图式 $10(+)$-氯马斯汀关键中间体的合成

Scheme 10 Synthesis of the $(+)$-clemastine intermediate<smiles>CCCCC(=O)c1ccc(Cl)cc1Cl</smiles>
(S,S,S, S-WingPhos) (3.6 mol\%)

$\left[\mathrm{Rh}\left(\mathrm{C}_{2} \mathrm{H}_{4}\right)_{2} \mathrm{Cl}\right]_{2}(1.5 \mathrm{~mol} \%)$ $\mathrm{MgBr}_{2}, \mathrm{CsF}, \mathrm{MTBE}$ $70 \%$ yield, $>99 \%$ ee<smiles>OC(CCCl)(c1ccc(F)cc1)c1ccc(Cl)cc1Cl</smiles>

99
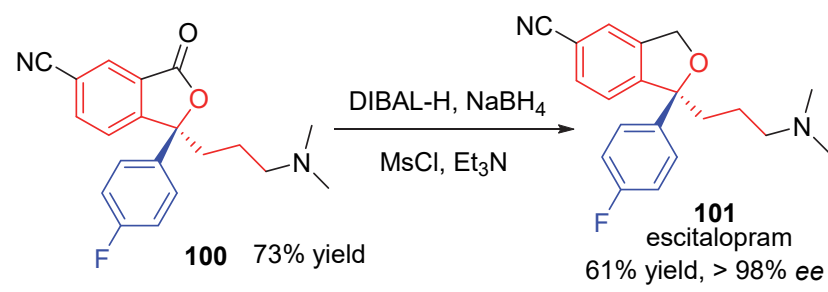

图式 11 西酞普兰的合成

Scheme 11 Synthesis of escitalopram 
法对于芳基酮、二芳基酮以及脂肪酮底物都可以取得较 好的收率，但是基本都只能得到消旋产物，仅有的一个 最好的结果为 $36 \%$ ee 值(Eq. 51).

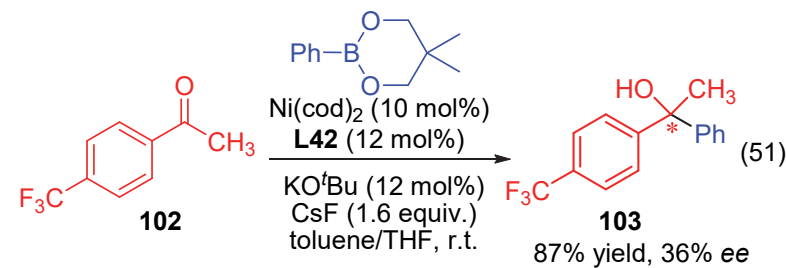<smiles>Cc1cc(Cl)cc(Cl)c1N1C[N+](c2c(C)cc(C3CCCCC3)cc2Cl)C(c2ccccc2)C1c1ccccc1</smiles>

\section{7 金属催化的芳基硼酸对非活泼酮的不对称分}

\section{子内加成}

酮的反应活性相对较弱, 因此反应相对较难. 而分 子内的反应由于反应位点之间碰撞的概率更高, 在一定 程度上可以弥补酮的反应活性较弱的问题, 并且分子内 加成相对于分子间的加成反应的位阻也更大，这一点对 提高反应的立体控制是有利的. 近年来也陆续有一些分 子内加成反应的报道, 也取得了不错的成果.

\section{1 钯催化的芳基硼酸对酮的分子内加成}

2006 年, 陆熙炎小组 ${ }^{[60]}$ 首次报道了阳离子钯催化 的分子内的芳基硼酸对酮的不对称加成(Eq. 52). 在以 离子交换树脂作为添加剂的条件下，反应能以最高 $91 \%$ 的收率得到最好为 $96 \% \mathrm{ee}$ 值的环化产物, 其中分子中

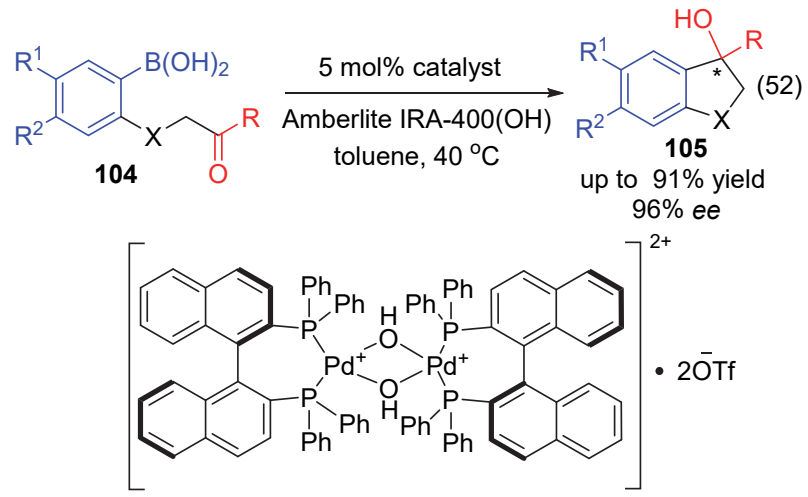

Selected examples:

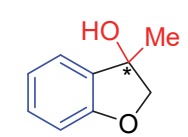

$58 \%$ yield, $96 \%$ ee

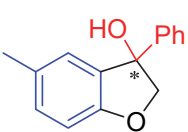

$82 \%$ yield, $93 \%$ ee

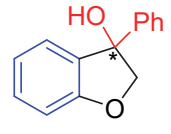

$85 \%$ yield, $92 \%$

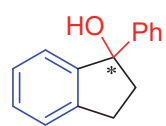

$53 \%$ yield, $66 \%$ ee

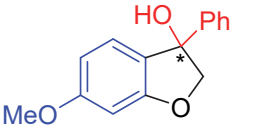

$91 \%$ yield, $89 \%$ ee

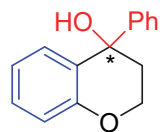

$82 \%$ yield, $53 \%$ ee

的连接基团氧被认为具有导向以及活化作用，当将氧换 成碳时, 反应的收率和立体选择性都出现大幅降低.

\section{2 铑催化的芳基硼酸对酮的不对称分子内加成}

2012 年, Sarpong 课题组 ${ }^{[61]}$ 报道了 $[\mathrm{Rh}(\mathrm{cod}) \mathrm{OH}]_{2}$ 与 手性二茂铁双膦配体催化的频哪醇硼酯对非活泼酮的 不对称分子内加成的例子, 用于构建高光学活性的手性 狮 1-醇类化合物 107 , 与陆小组工作 ${ }^{[60]}$ 不同的是, 该反 应体系对于碳链连接的酮效果更好(Eq. 53), 但当连接的 碳链进一步增加 1 个碳时反应结果又不够理想.

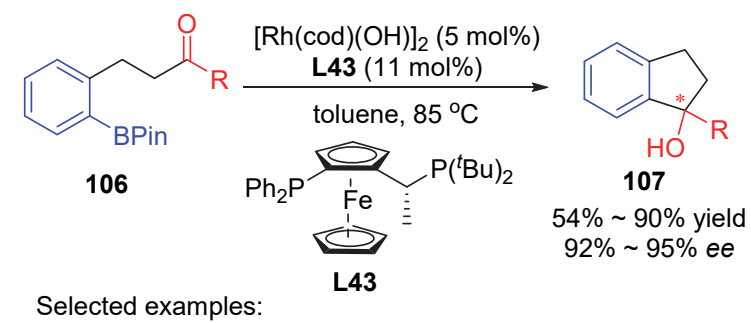

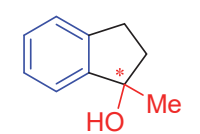

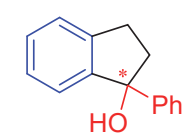

$90 \%$ yield, $95 \%$ ee

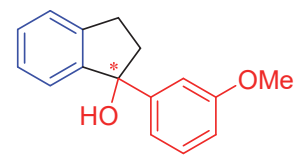

$85 \%$ yield, $95 \%$ ee

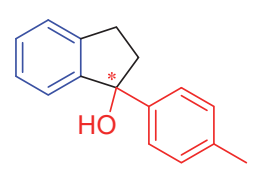

$90 \%$ yield, $94 \%$ ee

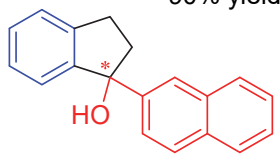

$50 \%$ yield, $93 \%$ ee
有意思的是, Lam 小组 ${ }^{[62]}$ 引入氮原子作为连接基团 设计了底物 108, 于同一时期报道了铑/硫烯配体 L44 催 化的分子内芳基硼酸对酮的不对称加成，高对映选择性 地构建了一系列苯并氮杂六元环类化合物 109 , 该方法 对于位阻较大的酮也能取得比较好的结果(Eq. 54).

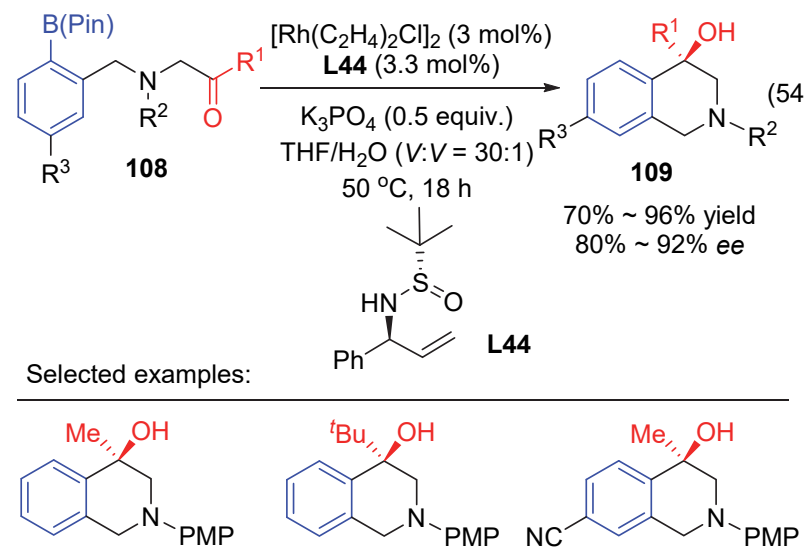

$82 \%$ yield, $89 \%$ ee

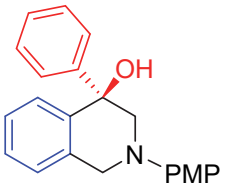

$92 \%$ yield, $87 \%$ ee
$95 \%$ yield, $80 \%$ ee<smiles>Cc1ccccc1[C@]1(O)CN(P(N)(=O)c2ccccc2)Cc2ccccc21</smiles>
95\% yield, $91 \%$ ee

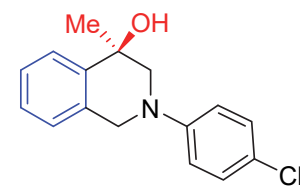

$96 \%$ yield, $88 \%$ ee 
2016 年, 徐明华课题组 ${ }^{[63]}$ 利用课题组发展的手性 硫烯配体 L45, 也实现了铑催化的非活泼酮 110 的分子 内的不对称芳基化. 在温和的反应条件下成功地实现了 一系列高光学活性的含季碳手性中心的 3-羟基苯并二 氢呋喃类化合物 111 的构建, 该反应体系不仅适合于芳 基酮，对于烷基酮也同时适用，而且对于 $\alpha$ 位双取代的 大位阻的酮也能取得不错的结果(Eq. 55).

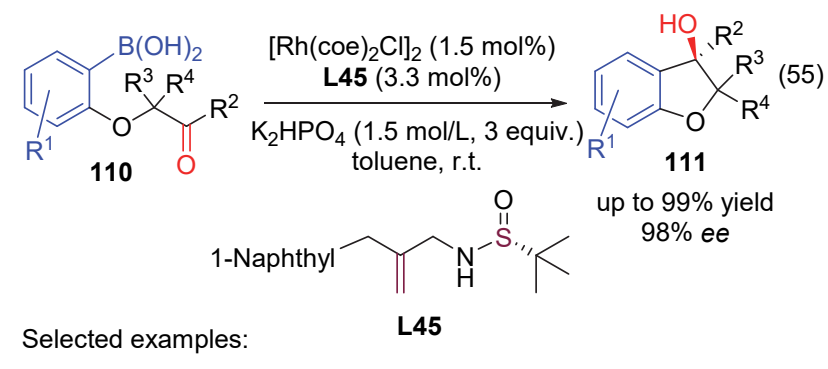

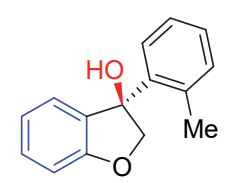

$91 \%$ yield, $95 \%$ ee

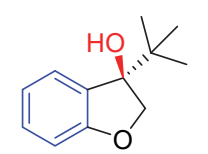

$99 \%$ yield, $97 \%$ ee

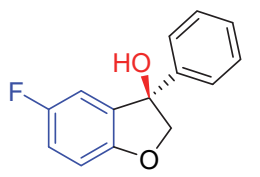

$99 \%$ yield, $94 \%$ ee

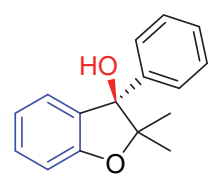

$95 \%$ yield, $92 \%$ ee

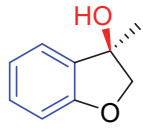

$63 \%$ yield, $98 \%$ ee

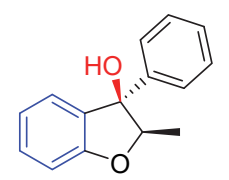

$49 \%$ yield, $93 \%$ ee

\section{8 总结与展望}

在过去的二十年里，过渡金属催化的有机硼试剂对 醛、酮的不对称加成研究取得了很大的进展, 特别是发 展了一系列高效的催化体系, 在一些较为活泼的羰基化 合物如 $\alpha$-芳基酮酸酯和 1,2-二芳基二酤类化合物的对映 选择性加成中取得了非常优秀的结果; 对靛红的加成虽 然也有一些不错的结果报道, 但反应的对映选择性受底 物和芳基硼试剂上取代基的影响较大. 值得关注的是, 简单醛、酮的高对映选择性加成仍是一个难点, 除了反 应活性较高的 2,2,2-三氟苯乙酮及其衍生物外, 大多数 醛、非活泼酮的催化不对称加成都难以取得理想的收率 和对映选择性, 或者存在明显的底物普适性问题, 仍有 很大的提升空间; 一些催化体系在分子内酮的不对称加 成反应中给出了不错的结果, 但同样受制于反应底物的 设计, 分子结构的局限性较大, 因此还有待有机化学家 们设计新的手性配体、发展高效的过渡金属催化体系来 突破这些瓶颈, 取得更好的结果. 另一方面, 我们也可 以看到, 与有机硼试剂对亚胺的不对称加成类似 ${ }^{[64]}$, 有 机嗍试剂对醛、酮的不对称加成研究也是主要集中在贵 金属铑和钯催化的反应中, 可喜的是, 其它过渡金属如
铱、钉, 以及更为廉价的铜、钴、镍等催化的有机硼试 剂对醛、酮的不对称加成研究已取得了一些成功, 虽然 目前一些反应的选择性仍不尽理想, 但相信随着化学家 们对反应机理和过渡态的理解和认识的深入, 通过进一 步合理设计新型手性配体，制备高效的金属络合物催化 剂，未来在这一领域取得突破值得期待.

\section{References}

[1] (a) Dhillon, S.; Scott, L. J.; Plosker, G. L. CNS Drugs 2006, 20, 763.

(b) Fournier, A. M.; Brown, R. A.; Farnaby, W.; Miyatake-Ondozabal, H.; Clayden, J. Org. Lett. 2010, 12, 2222.

(c) Nathan, L. A. J. Appl. Ther. 1962, 4, 830.

[2] Bai, D. L.; Chen, K. X.; Li, S. K.; Feng, S. Adv. Med. Chem. 2011, p. 290 (in Chinese).

(白东鲁, 陈凯先, 李树坤, 冯松, 高等药物化学, 2011, p. 290.)

[3] (a) Heravi, M. M.; Zadsirjan, V.; Esfandyari, M.; Lashaki, T. B. Tetrahedron: Asymmetry 2017, 28, 987.

(b) Zaitsev, A. B.; Adolfsson, H. Synthesis 2006, 1725.

(c) Scott, H. K.; Aggarwal, V. K. Chem. Eur. J. 2011, 17, 13124.

(d) Jacobsen, E. N.; Kakiuchi, F.; Konsler, R. G.; Larrow, J. F.; Tokunaga, F. Tetrahedron Lett. 1997, 38, 773.

(e) Wang, C.; Luo, L.; Yamamoto, H. Acc. Chem. Res. 2016, 49 , 193.

(f) Sälinger, D.; Brückner, R. Chem.-Eur. J. 2009, 15, 6688.

[4] (a) Hatano, M.; Ishihara, K. Synthesis 2008, 1647.

(b) Rong, J.; Pellegrini, T.; Harutyunyan, S. R. Chem. Eur. J. 2016, 22,3558 .

(c) Collados, J. F.; Sol, R.; Harutyunyan, S. R.; Macià, B. ACS Catal. 2016, 6, 1952.

(d) Pellissier, H. Tetrahedron 2015, 71, 2487.

(e) Liu, Y. L.; Lin, X. T. Adv. Synth. Catal. 2019, 361, 876.

[5] Sakai, M.; Ueda, M.; Miyaura, N. Angew. Chem., Int. Ed. 1998, 37, 3279 .

[6] (a) Jiang, Z. T.; Wang, B. Q.; Shi, Z. J. Chin. J. Chem. 2018, 36, 954.

(b) Wang, G. N.; Gan, Y.; Liu, Y. H. Chin. J. Chem. 2018, 36, 916.

[7] Focken, T.; Rudolph, J.; Bolm, C. Synthesis 2005, 429.

[8] (a) Suzuki, K.; Ishii, S.; Kondo, K.; Aoyama, T. Synlett 2006, 648. (b) Suzuki, K.; Kondo, K.; Aoyama, T. Synthesis 2006, 1360.

(c) Arao, T.; Suzuki, K.; Kondo, K.; Aoyama, T. Synthesis 2006, 3809.

[9] Duan, H. F.; Xie, J. H.; Shi, W. J.; Zhang, Q.; Zhou, Q. L. Org. Lett. 2006, $8,1479$.

[10] Jagt, R. B. C.; Toullec, P. Y.; de Vries, J. G.; Feringa, B. L.; Minnaard, A. J. Org. Biomol. Chem. 2006, 4, 773.

[11] (a) Noël, T.; Vandyck, K.; Van der Eycken, J. Tetrahedron 2007, 63, 12961.

(b) Nishimura, T.; Kumamoto, H.; Nagaosa, M.; Hayashi, T. Chem. Commun. 2009, 45, 5713.

[12] Morikawa, S.; Michigami, K.; Amii, H. Org. Lett. 2010, 12, 2520.

[13] (a) Ma, Q. S.; Ma, Y. D.; Liu, X.; Duan, W. Z.; Qu, B.; Song, C. Tetrahedron: Asymmetry 2010, 21, 292.

(b) Duan, W. Z.; Ma, Y. D.; Qu, B.; Zhao, L.; Chen, J. Q.; Song, C. Tetrahedron: Asymmetry 2012, 23, 1369.

(c) Duan, W. Z.; Ma, Y. D.; He, F. Y.; Zhao, L.; Chen, J. Q.; Song, C. Tetrahedron: Asymmetry 2013, 24, 241.

(d) Wang, D. X.; Ma, Y. D.; He, F. Y.; Duan, W. Z.; Zhao, L.; Song, C. Synth. Commun. 2013, 43, 810.

(e) Chen, J. Q.; Yang, S. B.; Chen, Z.; Song, C.; Ma, Y. D. Tetrahedron: Asymmetry 2015, 26, 288.

[14] He, W. P.; Zhou, B. H.; Zhou, Y. L.; Li, X. L.; Fan, L. M.; Shou, H. W.; Li, J. Tetrahedron Lett. 2016, 57, 3152.

[15] Kamikawa, K.; Tseng, Y.-Y.; Jian, J.-H.; Takahashi, T.; Ogasawara, 
M. J. Am. Chem. Soc. 2017, 139, 1545.

[16] (a) Yamamoto, Y.; Miyaura, N.; Kurihara, K. Angew. Chem., Int. Ed. 2009, 48, 4414.

(b) Shirai, T.; Watanabe, M.; Kurihara, K.; Miyaura, N.; Yamamoto, Y. Molecules 2011, 16, 5020.

(c) Yamamoto, Y.; Shirai, T.; Miyaura, N. Chem. Commun. 2012, 48, 2803.

[17] Desroches, J.; Ariane Tremblay, A.; Paquin, J.-F. Org. Biomol. Chem. 2016, 14, 8764.

[18] Li, K.; Hu, N. F.; Luo, R. S.; Yuan, W. C.; Tang, W. J. J. Org. Chem. 2013, 78, 6350.

[19] Lu, Z. W.; Zhang, H. Y.; Yang, Z. P.; Ding, N.; Meng, L.; Wang. J. ACS Catal. 2019, 9, 1457.

[20] (a) Arao, T.; Kondo, K.; Aoyama, T. Tetrahedron Lett. 2007, 48, 4115.

(b) Yamamoto, K.; Tsurumi, K.; Sakurai, F.; Kondo, K.; Aoyama, T. Synthesis 2008, 3585.

[21] Karthikeyan, J.; Jeganmohan, M.; Cheng, C.-H. Chem.-Eur. J. 2010, 16, 8989.

[22] (a) Suzuma, Y.; Hayashi, S.; Yamamoto, T.; Oe, Y.; Ohta, T.; Ito, Y. Tetrahedron: Asymmetry 2009, 20, 2751.

(b) Loxq, P.; Debono, N.; Gülcemal, S.; Daran, J-C.; Manoury, E.; Poli, R.; Cetinkaya, B.; Labande, A. New J. Chem. 2014, 38, 338.

(c) Zhang, R.; Xu, Q.; Zhang, X.; Zhang, T.; Shi, M. Tetrahedron: Asymmetry 2010, 21, 1928.

[23] (a) Tokunaga, T.; Hume, W. E.; Nagamine, J.; Kawamura, T.; Taiji, M.; Nagata, R. Bioorg. Med. Chem. Lett. 2005, 15, 1789.

(b) Tokunaga, T.; Hume, W. E.; Umezome, T.; Okazaki, K.; Ueki, Y.; Kumagai, K.; Hourai, S.; Nagamine, J.; Seki, H.; Taiji, M.; Noguchi, H.; Nagata, R. J. Med. Chem. 2001, 44, 4641.

[24] Di Malta, A.; Garcia, G.; Roux, R.; Schoentjes, B.; Serradeil-le Gal, C.; Tonnerre, B.; Wagnon, J. WO 2003008407, 2003

[25] Shintani, R.; Inoue, M.; Hayashi, T. Angew. Chem., Int. Ed. 2006, $45,3353$.

[26] Toullec, P. Y.; Jagt, R. B. C.; de Vries, J. G.; Feringa, B. L.; Minnaard, A. J. Org. Lett. 2006, 8, 2715.

[27] Gui, J.; Chen, G.; Cao, P.; Liao, J. Tetrahedron: Asymmetry 2012, 23,554 .

[28] (a) Feng, X. Q.; Du, H. F. Chin. J. Org. Chem. 2015, 35, 259 (in Chinese).

(冯向青，杜海峰，有机化学，2015, 35, 259.)

(b) Feng, X. Q.; Nie, Y. Z.; Zhang, L. Q.; Yang, J.; Du, H. F. Tetrahedron Lett. 2014, 55, 4581.

[29] Marques, C. S.; Burke, A. J. ChemCatChem 2016, 8, 3518.

[30] Lai, H. S.; Huang, Z. Y.; Wu, Q.; Qin, Y. J. Org. Chem. 2009, 74, 283.

[31] Liu, Z.; Gu, P.; Shi, M.; McDowell, P.; Li, G. G. Org. Lett. 2011, 13, 2314.

[32] Li, Q.; Wan, P.; Wang, S.; Zhuang, Y.; Li, L.; Zhou, Y.; He, Y.; Cao, R.; Qiu, L.; Zhou, Z. Appl. Catal., A 2013, 458, 201.

[33] (a) Yamamoto, Y.; Yohd, M.; Shirai, T.; Ito, H.; Miyaura, N. Chem. Asian J. 2012, 7, 2446.

(b) Yohda, M.; Yamamoto, Y. Tetrahedron: Asymmetry 2015, 26, 1430.

[34] Shintani, R.; Takatsu, K.; Hayashi, T. Chem. Commun. 2010, 46, 6822.

[35] Zhuang, Y.; He, Y. W.; Zhou, Z. H.; Xia, W.; Cheng, C. Y.; Wang, M.; Chen, B.; Zhou, Z. Y.; Pang, J. Y.; Qiu, L.Y. J. Org. Chem. 2015, 80, 6968 .

[36] (a) Skaddan, M. B.; Kilbourn, M. R.; Snyder, S. E.; Sherman, P. S.; Desmond, T. J.; Frey, K. A. J. Med. Chem. 2000, 43, 4552.

(b) Selent, J.; Brandt, W.; Pamperin, D.; Goeber, B. Bioorg. Med. Chem. 2006, 14, 1729

[37] Duan, H. F.; Xie, J. H. Qiao, X. C. Wang, L. X.; Zhou, Q. L. An- gew. Chem., Int. Ed. 2008, 47, 4351.

[38] Cai, F.; Pu, X. T.; Qi, X. B.; Lynch, V.; Radha, A.; Ready, J. M. J. Am. Chem. Soc. 2011, 133, 18066.

[39] (a) Zhu, T.-S.; Jin, S.-S.; Xu, M.-H. Angew. Chem., Int. Ed. 2012, 51,780 .

(b) Wang, H.; Zhu, T.-S.; Xu, M.-H. Org. Biomol. Chem. 2012, 10, 9158.

[40] Li, Y.; Zhu, D.-X.; Xu, M.-H. Chem. Commun. 2013, 49, 11659.

[41] Zhu, T.-S.; Xu, M.-H. Chin. J. Chem. 2013, 31, 321.

[42] Melcher, M.-C.; Ivšić, T.; Olagnon, C.; Tenten, C.; Letzen, A.; Strand, D. Chem.-Eur. J. 2018, 24, 2344.

[43] Chang, C.-A.; Uang, T.-Y.; Jian, J.-H.; Zhou, M.-Y.; Chen, M.-L.; Kuo, T.-S.; Wu, P.-Y.; Wu, H.-L. Adv. Synth. Catal. 2018, 360, 3381.

[44] Bartlett, S. L.; Keiter, K. M.; Johnson, J. S. J. Am. Chem. Soc. 2017, 139, 3911.

[45] Jung, J. K.; Johnson, B. R.; Duong, T.; Decaire, M.; Uy, J.; Gharbaoui, T.; Boatman, P. D.; Sage, C. R.; Chen, R.; Richman, J. G.; Connolly, D. T.; Semple, G. J. Med. Chem. 2007, 50, 1445.

[46] Singh, S. B.; Zink, D. L.; Quamina, D. S.; Pelaez, F.; Teran, A.; Felock, P.; Hazuda, D. J. Tetrahedron Lett. 2002, 43, 2351.

[47] Feng, X.; Nie, Y.; Yang, J.; Du, H. Org. Lett. 2012, 14, 624

[48] Wen, Q.; Zhang, L.; Xiong, J.; Zeng, Q. L. Eur. J. Org. Chem. 2016, 5360

[49] Zhu, T.-S.; Chen, J.-P.; Xu, M.-H. Chem. Eur. J. 2013, 19, 865.

[50] Zhang, Z.-F.; Zhu, D.-X.; Chen, W.-W.; Xu, B.; Xu, M.-H. Org. Lett. 2017, 19, 2726.

[51] Yu, Y.-N.; Xu, M.-H. Org. Chem. Front. 2014, 1, 738.

[52] (a) Rowley, M.; Hallett, D. J.; Goodacre, S.; Moyes, C.; Crawforth, J.; Sparey, T. J.; Patel, S.; Marwood, R.; Thomas, S.; Hitzel, L.; O'Connor, D.; Szeto, N.; Castro, J. L.; Hutson, P. H.; MacLeod, A. M. J. Med. Chem. 2001, 44, 1603.

(b) van Niel, M. B.; Collins, I.; Beer, M. S.; Broughton, H. B.; Cheng, S. K.; Goodacre, S. C.; Heald, A.; Locker, K. L.; MacLeod, A. M.; Morrison, D.; Moyes, C. R.; O'Connor, D.; Pike, A.; Rowley, M.; Russell, M. G.; Sohal, B.; Stanton, J. A.; Thomas, S.; Verrier, H.; Watt, A. P.; Castro, J. L. J. Med. Chem. 1999, 42, 2087.

(c) Domagala, J. M.; Hanna, L. D.; Heifetz, C. L.; Hutt, M. P.; Mich, T. F.; Sanchez, J. P.; Solomon, M. J. Med. Chem. 1986, 29 , 394.

(d) Rosenblum, S. B.; Huynh, T.; Afonso, A.; Davis, H. R. Jr.; Yumibe, N.; Clader, J. W.; Burnett, D. A. J. Med. Chem. 1998, 41, 973.

[53] Martina, S. L. X.; Jagt, R. B. C.; Vries, J. G.; Feringa B. L.; Minnaard, A. J. Chem. Commun. 2006, 42, 4093.

[54] Jumde, V. R.; Facchetti, S.; Iuliano, A. Tetrahedron: Asymmetry 2010, 21, 2775.

[55] Luo, R. S.; Li, K.; Hu, Y. L.; Tang, W. J. Adv. Synth. Catal. 2013, 355, 1297.

[56] Korenaga, T.; Ko, A.; Uotani, K.; Tanaka, Y.; Sakai, T. Angew. Chem., Int. Ed. 2011, 50, 10703.

[57] Liao, Y. X.; Xing, C. H.; Hu, Q. S. Org. Lett. 2012, 14, 1544.

[58] Huang, L. W.; Zhu, J. B.; Jiao, G. J.; Wang, Z.; Yu, X. X.; Deng, W. P.; Tang, W. J. Angew. Chem., Int. Ed. 2016, 55, 4527.

[59] Bouffard, J.; Itami, K. Org. Lett. 2009, 11, 4410.

[60] Liu, G. X.; Lu, X. Y. J. Am. Chem. Soc. 2006, 128, 16504.

[61] Gallego, G. M.; Sarpong, R. Chem. Sci. 2012, 3, 1338.

[62] Low, D. W.; Pattison, G.; Wieczysty, M. D.; Churchill, G. H.; Lam, H. W. Org. Lett. 2012, 14, 2548.

[63] Zhu, D.-X.; Chen, W.-W.; Xu, M.-H. Tetrahedron 2016. 72, 2037.

[64] Chen, D.; Xu, M.-H. Chin. J. Org. Chem. 2017, 37, 1589 (in Chinese).

(陈雕，徐明华，有机化学, 2017, 37, 1589.) 